\title{
JV TASK 27 - VALIDATION OF MERCURY CEMS WHEN COFIRING BIOMASS AT MADISON ELECTRIC'S BLOUNT STATION
}

\section{Final Topical Report}

Prepared for:

AAD Document Control

National Energy Technology Laboratory

US Department of Energy

PO Box 10940

626 Cochrans Mill Road MS 921-217Building 921

Pittsburgh, PA 15236-0940

DOE Cooperative Agreement No. DE-FC26-98FT40321

Performance Monitor: Dr. Richard Read

Prepared by:

Dennis L. Laudal Jeffrey S. Thompson

Energy \& Environmental Research Center

PO Box 9018

Grand Forks, ND 58202-9018 


\section{DISCLAIMER}

This report was prepared as an account of work sponsored by an agency of the United States Government. Neither the United States Government, nor any agency thereof, nor any of their employees makes any warranty, express or implied, or assumes any legal liability or responsibility for the accuracy, completeness, or usefulness of any information, apparatus, product, or process disclosed or represents that its use would not infringe privately owned rights. Reference herein to any specific commercial product, process, or service by trade name, trademark, manufacturer, or otherwise does not necessarily constitute or imply its endorsement, recommendation, or favoring by the United States Government or any agency thereof. The views and opinions of authors expressed herein do not necessarily state or reflect those of the United States Government or any agency thereof.

This report is available to the public from the National Technical Information Service, U.S. Department of Commerce, 5285 Port Royal Road, Springfield, VA 22161; phone orders accepted at (703) $487-4650$.

\section{ACKNOWLEDGMENT}

This report was prepared with the support of the U.S. Department of Energy (DOE) National Energy Technology Laboratory under Cooperative Agreement No. DE-FC26-98FT40321 and EPRI under Contract No. WO9211-03. However, any opinions, findings, conclusions, or recommendations expressed herein are those of the authors(s) and do not necessarily reflect the views of DOE or EPRI.

\section{EERC DISCLAIMER}

LEGAL NOTICE This research report was prepared by the Energy \& Environmental Research Center (EERC), an agency of the University of North Dakota, as an account of work sponsored by DOE and EPRI. Because of the research nature of the work performed, neither the EERC nor any of its employees makes any warranty, express or implied, or assumes any legal liability or responsibility for the accuracy, completeness, or usefulness of any information, apparatus, product, or process disclosed, or represents that its use would not infringe privately owned rights. Reference herein to any specific commercial product, process, or service by trade name, trademark, manufacturer, or otherwise does not necessarily constitute or imply its endorsement or recommendation by the EERC. 


\section{TABLE OF CONTENTS}

LIST OF FIGURES $\ldots \ldots \ldots \ldots \ldots \ldots \ldots \ldots \ldots \ldots \ldots \ldots \ldots \ldots \ldots \ldots$

LIST OF TABLES $\ldots \ldots \ldots \ldots \ldots \ldots \ldots \ldots \ldots \ldots \ldots \ldots \ldots \ldots \ldots \ldots \ldots \ldots$

EXECUTIVE SUMMARY $\ldots \ldots \ldots \ldots \ldots \ldots \ldots \ldots \ldots \ldots \ldots \ldots \ldots \ldots \ldots \ldots$

$1.0 \quad$ INTRODUCTION $\ldots \ldots \ldots \ldots \ldots \ldots \ldots \ldots \ldots \ldots \ldots \ldots \ldots \ldots \ldots \ldots \ldots$

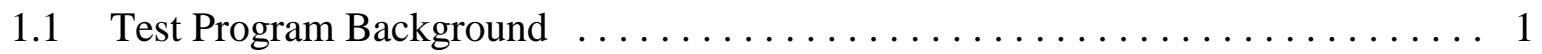

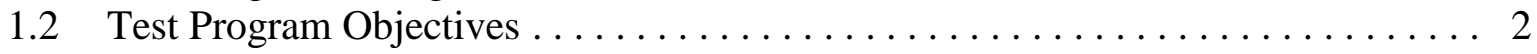

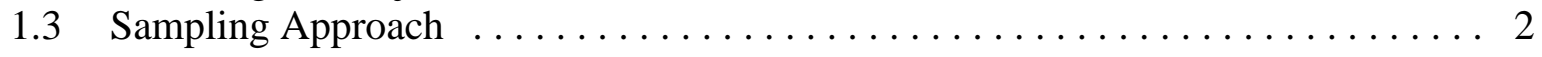

2.0 PROCESS DESCRIPTION $\ldots \ldots \ldots \ldots \ldots \ldots \ldots \ldots \ldots \ldots \ldots \ldots \ldots \ldots$

2.1 Sampling Test Plan, Locations, and Collection Procedures . . . . . . . . . 5

2.2 Process Operation During Testing $\ldots \ldots \ldots \ldots \ldots \ldots \ldots \ldots \ldots \ldots$

3.0 FLUE GAS SAMPLING AND ANALYTICAL METHODS $\ldots \ldots \ldots \ldots \ldots \ldots \ldots$

3.1 Ontario Hydro Mercury Speciation Method $\ldots \ldots \ldots \ldots \ldots \ldots \ldots \ldots \ldots \ldots$

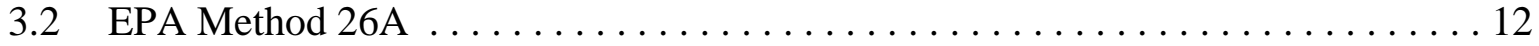

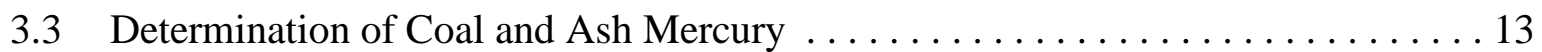

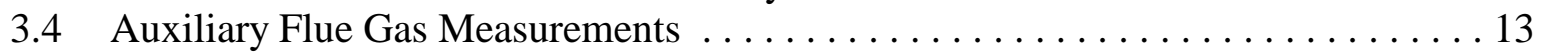

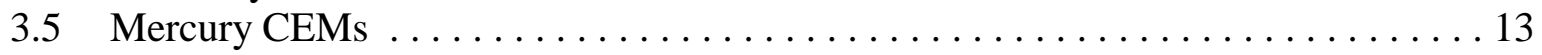

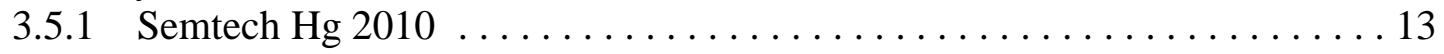

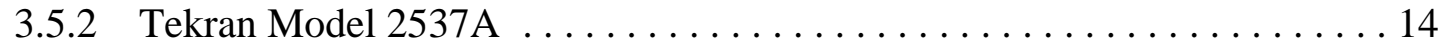

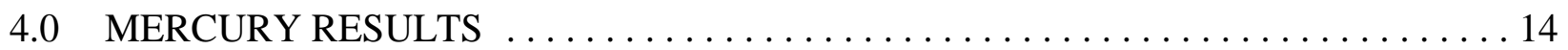

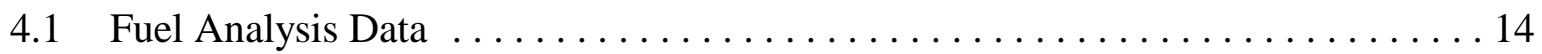

4.2 ESP Ash and Sample Filter Mercury $\ldots \ldots \ldots \ldots \ldots \ldots \ldots \ldots \ldots \ldots \ldots$

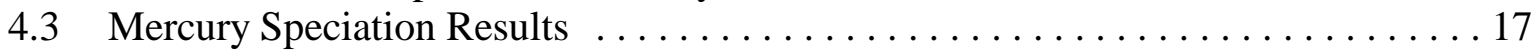

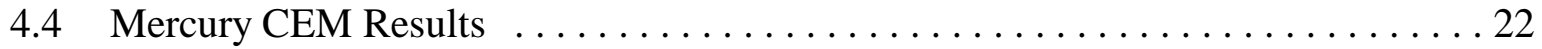

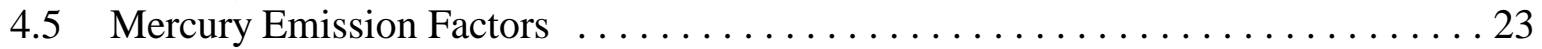

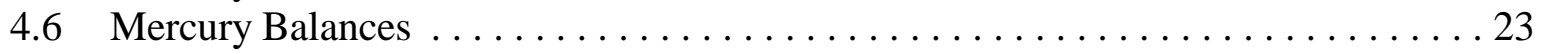

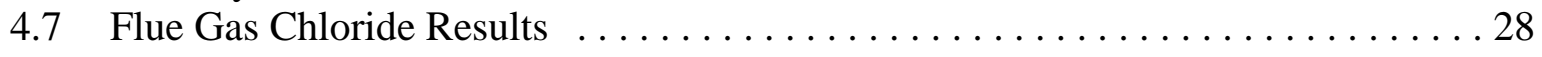

5.0 QUALITY ASSURANCE/QUALITY CONTROL . . . . . . . . . . . . . . . 29

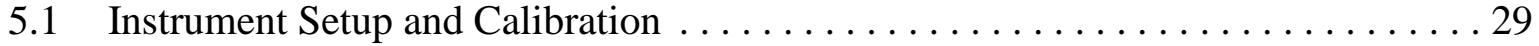



5.3 Glassware and Plasticware Cleaning and Storage $\ldots \ldots \ldots \ldots \ldots \ldots \ldots \ldots$

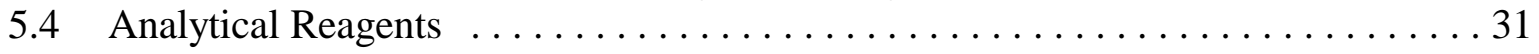

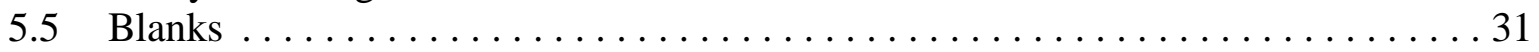

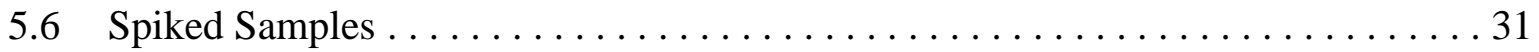

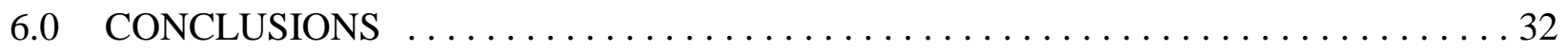

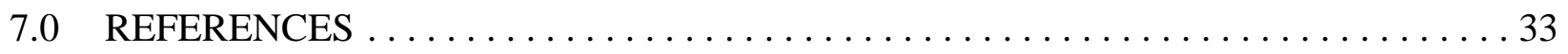




\section{LIST OF FIGURES}

1 Schematic of Unit 9 Blount Station and sampling locations $\ldots \ldots \ldots \ldots$

2 Schematic of the sampling train $\ldots \ldots \ldots \ldots \ldots \ldots \ldots \ldots \ldots \ldots \ldots$

3 Sample recovery scheme for the mercury speciation sampling train $\ldots \ldots \ldots \ldots 11$

4 A schematic of the EPA Method 26A impinger train that was used for chloride

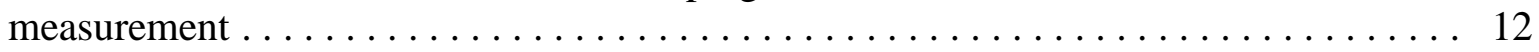

$5 \quad$ Mercury removal across the ESP with coal only $\ldots \ldots \ldots \ldots \ldots \ldots \ldots \ldots$

6 Mercury removal across the ESP with coal and paper $\ldots \ldots \ldots \ldots \ldots \ldots$

7 Mercury removal across the ESP with coal and plastic $\ldots \ldots \ldots \ldots \ldots \ldots$

8 Mercury removal across the ESP with coal, paper, and plastic $\ldots \ldots \ldots \ldots \ldots$

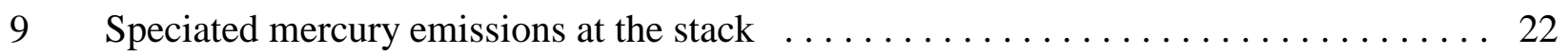

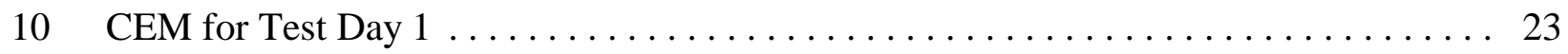

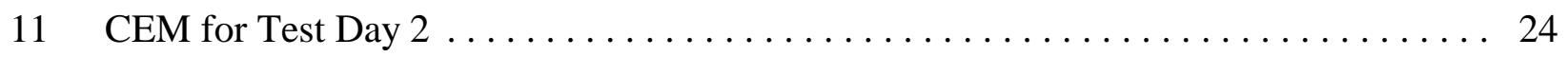

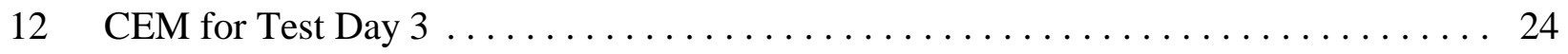

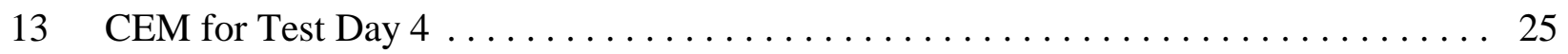

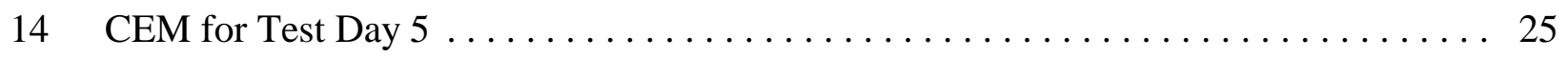

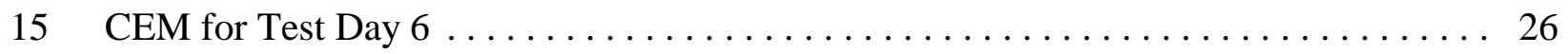

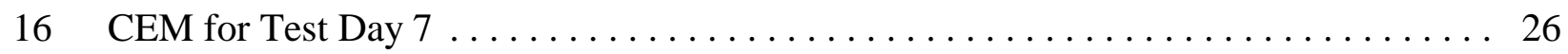

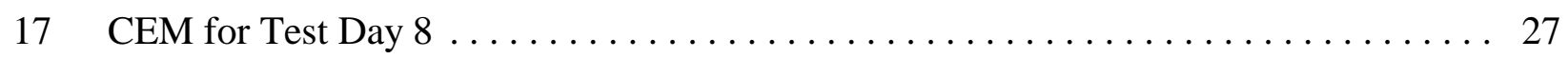




\section{LIST OF TABLES}

1 Mercury Speciation Test Program Matrix $\ldots \ldots \ldots \ldots \ldots \ldots \ldots \ldots \ldots \ldots$

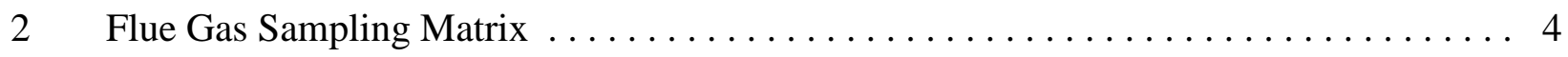

3 Particulate Removal Efficiency Summary $\ldots \ldots \ldots \ldots \ldots \ldots \ldots \ldots \ldots \ldots \ldots \ldots$

4 Particulate Collection Efficiency During Mercury Sampling $\ldots \ldots \ldots \ldots \ldots \ldots$

5 Blount Station Unit 9 Operating Conditions Summary, Coal Only $\ldots \ldots \ldots \ldots \ldots \ldots$

6 Blount Station Unit 9 Operating Conditions Summary, Coal and Paper ........... 8

7 Blount Station Unit 9 Operating Conditions Summary, Coal and Plastic $\ldots \ldots \ldots \ldots 8$

8 Blount Station Unit 9 Operating Conditions Summary, Blend $\ldots \ldots \ldots \ldots \ldots \ldots$

9 Sample Train Components - EPA Method 17 Configuration $\ldots \ldots \ldots \ldots \ldots \ldots$

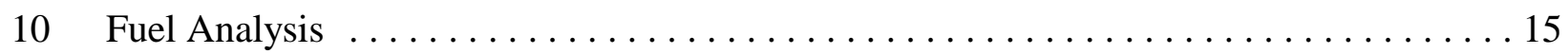

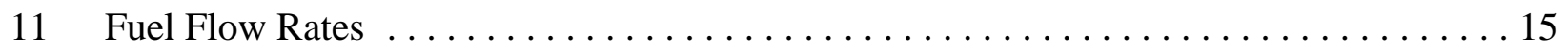

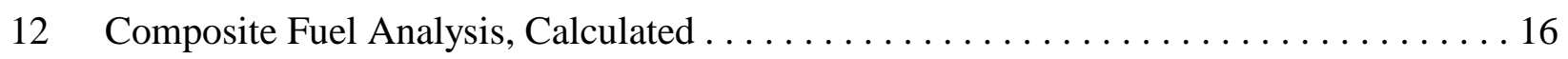

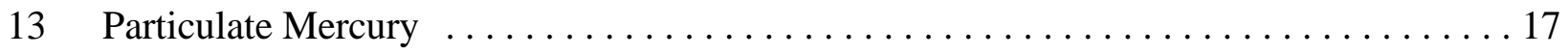

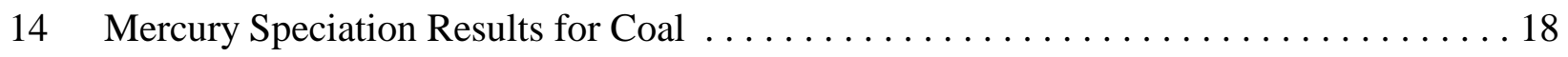

15 Mercury Speciation Results for Coal plus Paper ........................ 18

16 Mercury Speciation Results for Coal plus Plastic $\ldots \ldots \ldots \ldots \ldots \ldots \ldots \ldots \ldots$

17 Mercury Speciation Results for Coal, Paper, and Plastic Blend . . . . . . . . . . . . . 19

18 Concentration of Vapor-Phase Mercury Across the ESP ................... 21

19 Effect of PDF on Outlet Vapor-Phase Mercury Species $\ldots \ldots \ldots \ldots \ldots \ldots \ldots \ldots 22$

20 Emission Factors for Mercury at the Outlet of the ESP Firing Coal $\ldots \ldots \ldots \ldots \ldots 27$

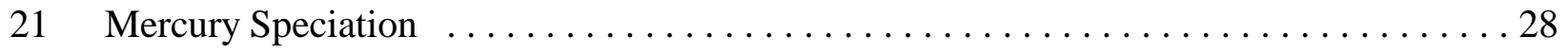

continued... 


\section{LIST OF TABLES (continued)}

22 Mercury Flow Rates and Balances . . . . . . . . . . . . . . . . . . . . . . . 29

23 Chloride Concentrations in the Flue Gas . . . . . . . . . . . . . . . . 30

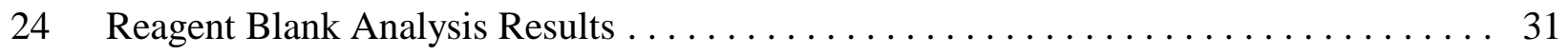

25 Results of Mercury Speciation Field Blanks $\ldots \ldots \ldots \ldots \ldots \ldots \ldots \ldots \ldots \ldots \ldots$

26 Summary of Results of Mercury Speciation Spikes . . . . . . . . . . . . . . . . 32 


\section{VALIDATION OF MERCURY CEMS WHEN COFIRING BIOMASS AT MADISON ELECTRIC'S BLOUNT STATION}

\section{EXECUTIVE SUMMARY}

The 1990 Clean Air Act Amendments required the U.S. Environmental Protection Agency (EPA) to determine whether the presence of mercury in the stack emissions from fossil fuel-fired electric utility power plants poses an unacceptable public health risk. EPA's conclusions and recommendations were presented in the Mercury Study Report to Congress and Study of Hazardous Air Pollutant Emissions from Electric Utility Steam Generating Units (1). The first report addressed both the human health and environmental effects of anthropogenic mercury emissions, while the second addressed the risk to public health posed by the emission of mercury and other hazardous air pollutants from steam electric generating units. Although these reports did not state that mercury controls on coal-fired electric power stations would be required given the current state of the art, they did indicate that EPA views mercury as a potential threat to human health. Therefore, it was concluded that mercury controls at some point may be necessary. EPA also indicated that additional research/information was necessary before any definitive statement could be made.

The state of Wisconsin has been concerned about mercury deposition into its lakes and streams and has been evaluating strategies to reduce mercury emissions. As part of this effort, the Blount Station, owned and operated by Madison Gas and Electric Company (MGE), has undergone a project to evaluate the effects and potential mercury emissions reduction of cofiring preconsumer waste.

MGE owns and operates the Blount Generating Station located in central Madison, Wisconsin. At present, Blount operates with nine boilers and six turbine generators. The two largest boilers at Blount produce 400,000 pounds of steam per hour at $950^{\circ} \mathrm{F}$ and 1250 psi. These larger boilers, MGE's Boiler Nos. 8 and 9, have the capability of cofiring both paper and plastic. MGE's Blount Generating Station was one of the first electric generating stations in the United States to retrofit its existing steam boilers to successfully burn refuse-derived fuel and other alternate fuels including waste paper and wood. It is the No. 9 boiler that was the focus of this project to determine the effect of cofiring PDF (plastic- and paper-derived fuel) on speciated mercury emissions.

The project was laid out to compare four different fuel combinations: 1) coal feed only, 2) coal with plastic, 3) coal with paper, and 4) coal with paper and plastic. The design was to run the boiler for 2 days at each condition, thus allowing four samples to be taken at each condition. This plan was aimed at getting at least three representative samples at each condition and allowed for difficulties in sampling and boiler operation.

The following objectives were accomplished as part of the project to determine the effects of cofiring PDF on mercury emissions and speciation at MGE Blount Station:

- Successfully completed all of the mercury sampling for each of the four boiler/PDF conditions using the Ontario Hydro $(\mathrm{OH})$ mercury speciation method.

- Determined mercury concentrations at the stack location using mercury continuous emission monitors (CEMs) for each of the four boiler/PDF conditions.

- Calculated the overall mercury mass balance for each of the runs. 
- Determined chlorine concentrations at the stack location using EPA Method 26A for each of the four boiler/PDF conditions.

- Calculated speciated mercury flow to determine removal and/or transformations before its exiting the unit at the stack for each of the four boiler/PDF conditions.

The average flue gas mercury speciation results across the electrostatic precipitator (ESP) for each of the four fuel conditions are shown in Table ES-1. All data are based on $68^{\circ} \mathrm{F}$, dry conditions, and adjusted to $3 \%$ oxygen. The data show that for the Blount Station, the mercury at the stack is a mixture of both $\mathrm{Hg}^{0}$ and $\mathrm{Hg}^{2+}$. For all fuel conditions, the percentage of particulate-bound mercury is high, and the ESP essentially removes all of the particulate-bound mercury. Although it is clear there is a substantial reduction in mercury emissions when PDFs are burned compared to coal, the average removal across the ESP seems to be independent of fuel. The average removal was about $40 \%$.

For all conditions, burning PDF along with the coal decreased the concentration of mercury in the flue gas compared to burning the coal only. Moreover, at the stack, each of the vapor-phase species is also reduced compared to burning the coal only. Figure ES-1 shows the speciated mercury at the stack for the four operating conditions.

On the basis of the results from the sampling program at the Blount Station, the following conclusions can be made:

- Regardless of fuel, about $40 \%$ of the mercury generated at the Blount Station is in the form of particulate-bound mercury and is removed by the ESP.

- For all fuel conditions, there was an increase in measured vapor-phase mercury across the ESP. Most likely, this was due to additional mercury capture by the fly ash collected on the $\mathrm{OH}$ method filter.

- Good mass balances were obtained for each test condition.

- Adding PDF to the coal resulted in decreased mercury emissions at the stack.

Table ES-1. Average Mercury Speciation Results

$\underline{\text { ESP Inlet } \quad \text { ESP Outlet }}$

\begin{tabular}{|c|c|c|c|c|c|c|c|c|}
\hline & $\begin{array}{c}\text { Total Hg } \\
\mu \mathrm{g} / \mathrm{Nm}^{3}\end{array}$ & $\begin{array}{l}\mathrm{Hg}(\mathbf{p})^{\mathrm{a}}, \\
\mu \mathrm{g} / \mathrm{Nm}^{3}\end{array}$ & $\begin{array}{c}\mathrm{Hg}^{0}, \\
\mu \mathrm{g} / \mathrm{Nm}^{3}\end{array}$ & $\begin{array}{c}\mathrm{Hg}^{2+}, \\
\mu \mathrm{g} / \mathrm{Nm}^{3}\end{array}$ & \begin{tabular}{|} 
Total Hg, \\
$\mu \mathrm{g} / \mathrm{Nm}^{3}$
\end{tabular} & $\begin{array}{l}\mathrm{Hg}(\mathbf{p})^{\mathrm{a}}, \\
\mu \mathrm{g} / \mathrm{Nm}^{3}\end{array}$ & $\begin{array}{c}\mathrm{Hg}^{0}, \\
\mu \mathrm{g} / \mathrm{Nm}^{3}\end{array}$ & $\begin{array}{c}\mathrm{Hg}^{2+}, \\
\mu \mathrm{g} / \mathrm{Nm}^{3}\end{array}$ \\
\hline Coal & 5.16 & 3.20 & 0.22 & 1.73 & 3.20 & 0.007 & 1.21 & 1.98 \\
\hline Coal plus Paper & 2.76 & 2.41 & 0.21 & 0.15 & 1.52 & 0.004 & 0.81 & 0.71 \\
\hline Coal plus Plastic & 3.22 & 2.04 & 0.38 & 0.80 & 2.13 & 0.006 & 0.88 & 1.24 \\
\hline Coal plus Blend & 2.98 & 2.45 & 0.25 & 0.27 & 1.45 & 0.030 & 0.79 & 0.64 \\
\hline
\end{tabular}

a Particulate-bound $\mathrm{Hg}$. 


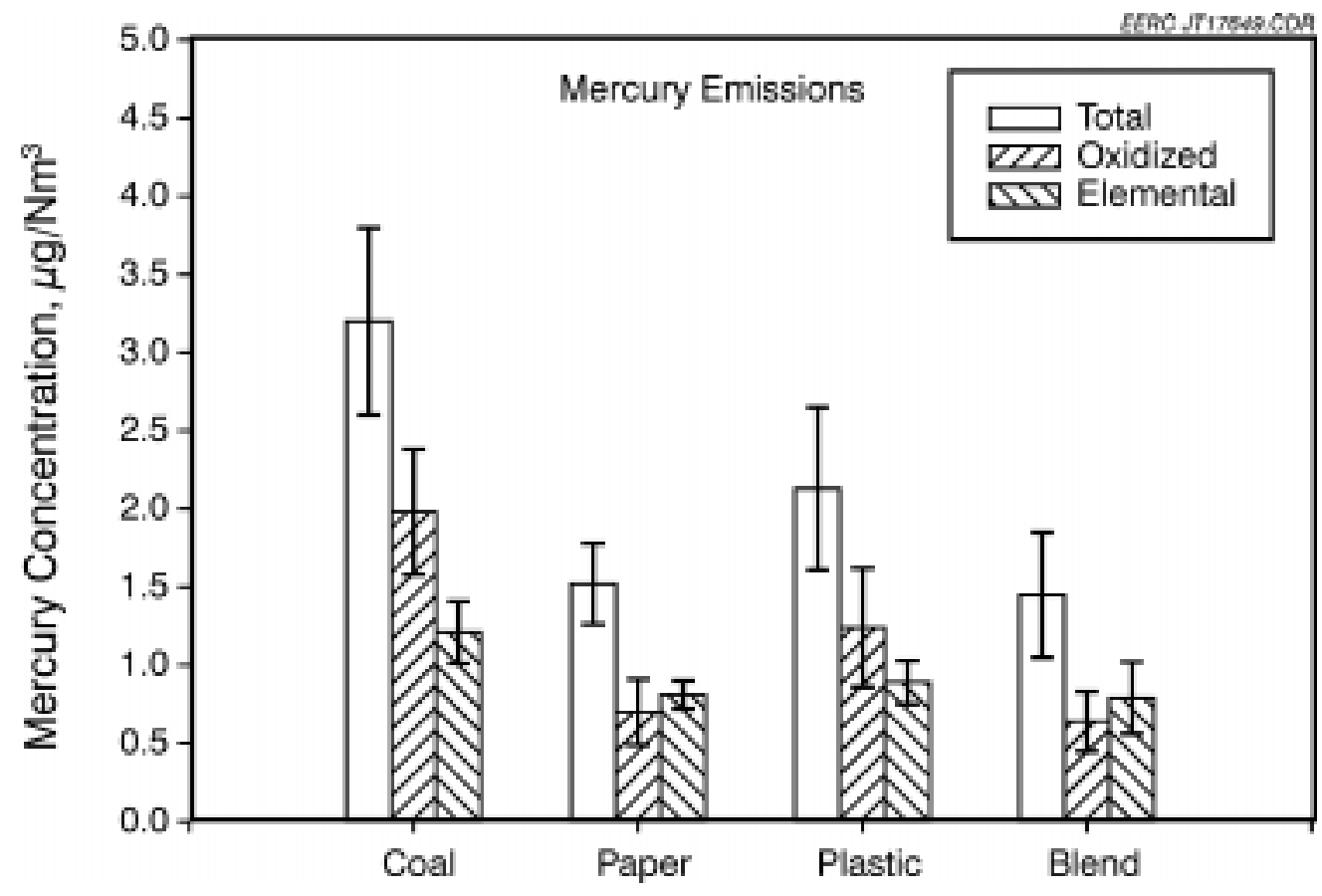

Figure ES-1. Speciated mercury emissions at the stack.

- The addition of paper to the fuel mix resulted in greater mercury reduction than plastic.

- As would be expected, the addition of a high-chloride plastic to the fuel mix increased the level of chloride in the flue gas. But this increase did not appear to affect mercury speciation.

- The Semtech Hg 2010 and the Tekran CEMs both gave good total mercury results when compared to the $\mathrm{OH}$ method. Although limited data were obtained, both CEMs gave good speciation results. 


\section{VALIDATION OF MERCURY CEMS WHEN COFIRING BIOMASS AT MADISON ELECTRIC'S BLOUNT STATION}

\subsection{INTRODUCTION}

\subsection{Test Program Background}

The 1990 Clean Air Act Amendments required the U.S. Environmental Protection Agency (EPA) to determine whether the presence of mercury in the stack emissions from fossil fuel-fired electric utility power plants poses an unacceptable public health risk. EPA's conclusions and recommendations were presented in the Mercury Study Report to Congress and Study of Hazardous Air Pollutant Emissions from Electric Utility Steam Generating Units (1). The first report addressed both the human health and environmental effects of anthropogenic mercury emissions, while the second addressed the risk to public health posed by the emission of mercury and other hazardous air pollutants from steam electric generating units. Although these reports did not state that mercury controls on coal-fired electric power stations would be required given the current state of the art, they did indicate that EPA views mercury as a potential threat to human health. Therefore, it was concluded that mercury controls at some point may be necessary. EPA also indicated that additional research/information was necessary before any definitive statement could be made.

The state of Wisconsin has been concerned about mercury deposition into its lakes and streams and has been evaluating strategies to reduce mercury emissions. As part of this effort, the Blount Station, owned and operated by Madison Gas and Electric Company (MGE), has taken part in a project to evaluate the effects and potential mercury emissions reduction of cofiring preconsumer waste.

This document serves as the final report for the activities resulting from measuring the speciated mercury emissions at MGE Blount Station. The document includes a plant description, sampling location information, unit operating information, descriptions of the sampling and analytical methods, quality assurance/quality control $(\mathrm{QA} / \mathrm{QC})$ activities, data from the mercury speciation sampling, and a summary and discussion of results.

MGE owns and operates the Blount Generating Station located in central Madison, Wisconsin. This plant is generally used as a load-following plant, operating at $40 \%$ peaking and $60 \%$ intermediate. The original Blount Station went into commercial operation in 1922. Blount meets air quality, water quality, and waste disposal standards set by both state and federal regulations. Hot gases and ash produced in the Blount boilers pass through mechanical and electrostatic precipitators (ESPs) that remove particulate matter before going to the stacks. By burning low-sulfur coal, cleanburning natural gas, and alternate fuels and using effective pollution control equipment, MGE minimizes the environmental impact of electricity generation.

At present, Blount operates with nine boilers and six turbine generators. The two largest boilers at Blount produce 400,000 pounds of steam per hour at $950^{\circ} \mathrm{F}$ and $1250 \mathrm{psi}$. These larger boilers, MGE's Boiler Nos. 8 and 9, have the capability of cofiring both paper and plastic. MGE's Blount Generating Station was one of the first electric generating stations in the United States to 
retrofit its existing steam boilers to successfully burn refuse-derived fuel and other alternate fuels including waste paper and wood. It is the No. 9 boiler that was the focus of this project to determine the effect of cofiring PDF (plastic- and paper-derived fuel) on speciated mercury emissions.

The project was laid out to compare four different fuel combinations. The four combinations included the following: 1) coal feed only, 2) coal with plastic, 3) coal with paper, and 4) coal with paper and plastic. The design was to run the boiler for 2 days at each condition, thus allowing four samples to be taken at each condition. This plan was aimed at getting at least three representative samples at each condition and allowed for difficulties in sampling and boiler operation.

\subsection{Test Program Objectives}

The following objectives were accomplished as part of the project to determine the effects of cofiring PDF on mercury emissions and speciation at MGE Blount Station:

- Successfully completed all of the mercury sampling for each of the four boiler/PDF conditions using the Ontario Hydro $(\mathrm{OH})$ mercury speciation method.

- Determined mercury concentrations at the stack location using mercury continuous emission monitors (CEMs) for each of the four boiler/PDF conditions.

- Calculated the overall mercury mass balance for each of the runs.

- Determined chlorine concentrations at the stack location using EPA Method 26A for each of the four boiler/PDF conditions.

- Calculated speciated mercury flow to determine removal and/or transformations before its exiting the unit at the stack for each of the four boiler/PDF conditions.

\subsection{Sampling Approach}

During the month of April 2000 (10th-18th), sampling was done at the Blount Station on Boiler No. 9 while boiler operations were managed to produce the specified conditions of cofiring PDF. For each of the boiler conditions, measurements using the $\mathrm{OH}$ speciation method were completed to determine speciated mercury emissions so that mercury removal and/or transformations across the ESP could be determined. Table 1 shows the test matrix for mercury sampling. These samples included the fuel feed, ash samples, and flue gas samples at the inlet to the ESP and at the outlet of the ESP (stack location). In addition, mercury CEMs were operated at the stack location. The CEMs were operated to verify the gas-phase mercury concentration at the stack location. Using these data, a mass balance of mercury was completed for the unit running under each of the four test conditions. 
Table 1. Mercury Speciation Test Program Matrix

\begin{tabular}{lc}
\hline Process Stream & Target Mercury Samples \\
\hline Flue Gas Sample Streams & \\
ESP Inlet & Speciated mercury \\
ESP Outlet & Speciated mercury \\
Solid Samples & \\
Coal Feeders & Total mercury \\
PDF Feeders & Total mercury \\
Dust Bin Ash & Total mercury \\
ESP Hopper Ash & Total mercury \\
\hline
\end{tabular}

Samples were taken to generate the following data:

- Particulate-bound, oxidized $\left(\mathrm{Hg}^{2+}\right)$, and elemental $\left(\mathrm{Hg}^{0}\right)$ mercury emissions at the ESP outlet using the $\mathrm{OH}$ speciation method.

- Particulate-bound, $\mathrm{Hg}^{2+}$, and $\mathrm{Hg}^{0}$ concentrations at the inlet to the ESP using the $\mathrm{OH}$ speciation method.

- Mercury and chlorine content of representative fuel samples collected from the coal and PDF feeders.

- Mercury content of fly ash samples collected from the dust bin (cyclone) and the ESP hoppers.

- Gas-phase mercury concentrations at the stack location using mercury CEMs concurrently with the $\mathrm{OH}$ mercury speciation method sampling.

- Chlorine emissions at the ESP outlet using EPA Method 26A.

Fuel samples were collected from the two coal feeders and the PDF feeders (after the shredders) and analyzed for mercury and chlorine content. In addition, fly ash samples were collected from the ESP hoppers and the cyclone hopper and analyzed for mercury to verify the concentration of particulate-bound mercury.

Table 2 shows the flue gas sampling matrix as completed for the four test conditions. 
Table 2. Flue Gas Sampling Matrix

\begin{tabular}{lcc}
\hline Fuel & Date $^{\mathrm{a}}$ & Samples \\
\hline Blend $^{\mathrm{b}}$ & $4 / 10 / 00$ & $2-\mathrm{OH}$ \\
Blend & $4 / 13 / 00$ & $2-\mathrm{OH}$ and M26A \\
Coal and Paper & $4 / 11 / 00$ & $2-\mathrm{OH}$ and M26A \\
Coal and Paper & $4 / 12 / 00$ & $2-\mathrm{OH}$ and M26A \\
Coal & $4 / 14 / 00$ & $2-\mathrm{OH}$ and M26A \\
Coal & $4 / 15 / 00$ & $\mathrm{OH}$ and M26A \\
Coal and Plastic & $4 / 17 / 00$ & $2-\mathrm{OH}$ and M26A \\
Coal and Plastic & $4 / 18 / 00$ & $2-\mathrm{OH}$ and M26A \\
\hline${ }^{\mathrm{a}}$ Because of problems with the plastic feeder, the test with paper and coal was completed prior to \\
finishing the blend tests.
\end{tabular}

\subsection{PROCESS DESCRIPTION}

The Blount Station, located in Madison, Wisconsin, consists of nine boilers which feed steam to six turbines. Boiler No. 9 is a Babcock \& Wilcox-manufactured pulverized coal-fired boiler with natural gas backup. The unit has six front-fired burners, and the boiler has a maximum gross output of $57 \mathrm{MW}$. The coal burned at this facility is an Indiana bituminous coal. Adjacent to the building housing the combustion unit is a PDF preparations building where both paper and plastic feedstock are shredded and fed into an air stream which is then fed into Boiler No. 9. This unit is limited by Title 5 permit restrictions to burning 30\% PDF based on heat input.

Boiler No. 9 at MGE Blount Station feeds steam to Turbine No. 7 to produce $40 \mathrm{MW}$ of electricity at nominal load. The boiler is fed from two coal pulverizers and an optional PDF feed. The flue gas exiting the boiler is ducted through an ID (induced-draft) fan prior to a two-stage ResearchCottrell cold-side ESP without any flue gas desulfurization system before exiting at the stack. A portion of the flue gas is cycled through a mechanical separator (cyclone particulate collector) prior to the ID fan. The sampling ports for the inlet to the ESP location are located just before the ID fan in a split duct. The sampling port for the stack location (outlet of the ESP) is located approximately 20 feet prior to the stack entrance. This location was used since the stack was not equipped with sampling ports and the sampling ports in the inlet duct to the stack were readily available. A schematic of the Unit 9 Blount Station and sampling locations is shown in Figure 1.

Key parameters include the following:

- Unit capacity: $57 \mathrm{MW}$ gross

- Boiler type: front-fired

- Fuel type: Indiana bituminous

- $\mathrm{SO}_{2}$ control: none 


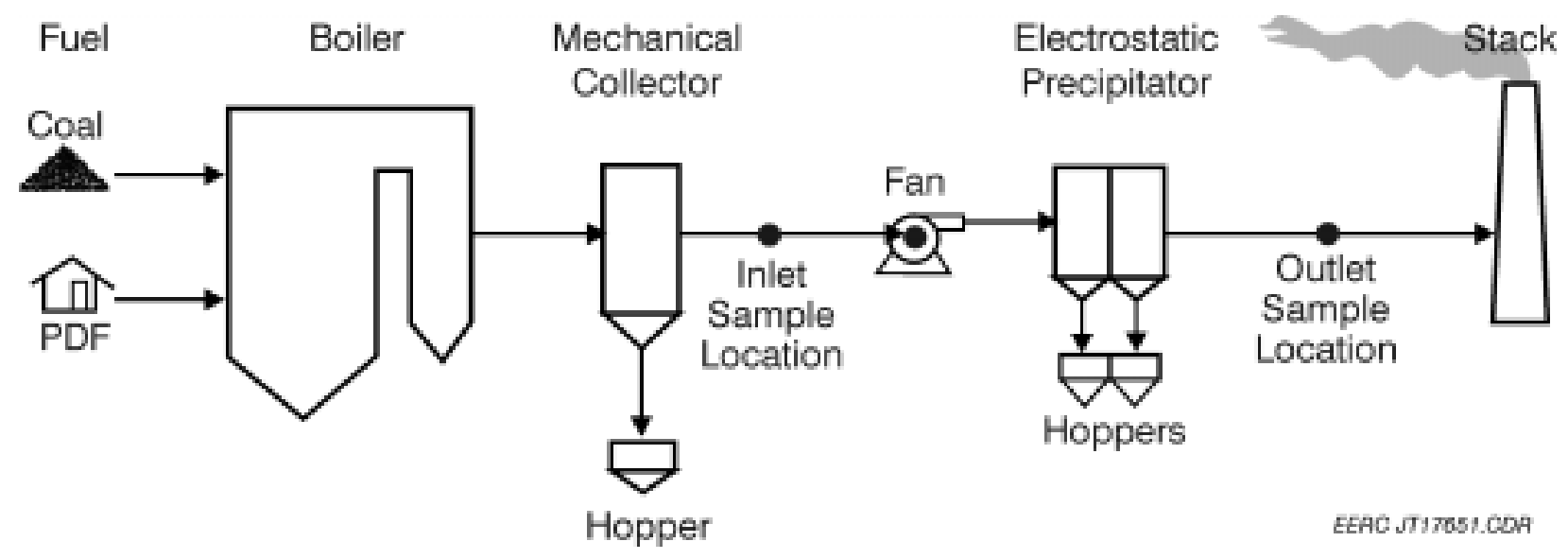

Figure 1. Schematic of Unit 9 Blount Station and sampling locations.

- Particulate control: ESP

- $\mathrm{NO}_{\mathrm{x}}$ control: (modified) low-NO $\mathrm{NO}_{\mathrm{x}}$ burners

Prior to and during each test, unit operation was assessed by the sampling team process monitor in conjunction with station personnel to ensure that operating conditions were within project target ranges. The efficiency of the mechanical dust collector (cyclone) and the two stages of the ESP was measured for regulatory purposes the week of February 9. The results of these particulate measurements are shown in Table 3. It should be noted that these results were obtained when Unit 9 was firing only coal. During mercury sampling, the particulate collection efficiency of the ESP was also measured. These results are shown in Table 4.

\subsection{Sampling Test Plan, Locations, and Collection Procedures}

As part of the test program sampling effort, mercury mass balances were required to be completed. Therefore, it was necessary to measure the flue gas mercury at the inlet of the ESP, as well as at the stack. Not only is it important to measure total mercury at the stack, but also the mercury speciation, because the rate of deposition of mercury in the environment is highly dependent on the type of mercury being emitted (2). In addition, measurement of mercury speciation at the inlet allows the determination of species removal and/or transformations across the ESP.

The location of the flue gas-sampling points for Unit 9 are represented by solid circles in Figure 1. To determine the effectiveness of the ESP at removing mercury released during combustion, the mercury concentration at the inlet and at the stack was measured. Because of the high dust loading at the inlet of the ESP, it was intended that the sampling follow EPA Method 1 protocols. However because the sampling ports were located near a bend, it was not possible to meet all of the EPA Method 1 sampling criteria at this location. At the ESP inlet, a 12-point traverse in a $3 \times 4$ grid was used for sample collection. At the stack, because of very low dust loading, it was anticipated that the mercury would be primarily in the gas phase; thus it was decided that only a single traverse point would be used for sample collection. 
Table 3. Particulate Removal Efficiency Summary

\begin{tabular}{|c|c|c|c|c|c|c|c|c|}
\hline \multicolumn{9}{|c|}{ Unit 9} \\
\hline \multirow[b]{2}{*}{$\begin{array}{l}\text { Test } \\
\text { No. }\end{array}$} & \multirow[b]{2}{*}{ Date } & \multicolumn{3}{|c|}{$\begin{array}{l}\text { Location: Mechanical Collector } \\
\text { Inlet }\end{array}$} & \multicolumn{3}{|c|}{ Location: ESP Inlet } & \multirow[b]{2}{*}{$\begin{array}{l}\text { Efficiency, } \\
\%\end{array}$} \\
\hline & & $\begin{array}{l}\text { Temp, } \\
{ }^{\circ} \mathbf{F}\end{array}$ & $\begin{array}{c}\text { Gas Volume, } \\
\text { dscfm }\end{array}$ & gr/dscf & $\begin{array}{l}\text { Temp, } \\
{ }^{\circ} \mathbf{F}\end{array}$ & $\begin{array}{c}\text { Gas Volume, } \\
\text { dscfm }\end{array}$ & gr/dscf & \\
\hline 1 & $2 / 9 / 00$ & 315 & 218,173 & 5.0943 & 318 & 189,207 & 2.0592 & 59.58 \\
\hline 2 & $2 / 9 / 00$ & 317 & 196,620 & 2.6201 & 314 & 187,190 & 1.2795 & 51.17 \\
\hline 3 & $2 / 9 / 00$ & 324 & 193,738 & 3.1993 & 323 & 190,633 & 1.5050 & 52.96 \\
\hline \multicolumn{2}{|c|}{ Average } & 319 & 202,844 & 3.6379 & 318 & 189,010 & 1.6146 & 54.57 \\
\hline & & \multicolumn{3}{|c|}{ Location: ESP Inlet } & \multicolumn{4}{|c|}{ Location: ESP Outlet (Field 1 only) } \\
\hline $\begin{array}{l}\text { Test } \\
\text { No. }\end{array}$ & Date & $\underset{{ }^{\circ} \mathbf{F}}{\text { Temp, }}$ & $\begin{array}{c}\text { Gas Volume, } \\
\text { dscfm }\end{array}$ & gr/dscf & $\underset{\mathrm{Temp}}{{ }^{\circ} \mathbf{F}}$ & $\begin{array}{c}\text { Gas Volume, } \\
\text { dscfm }\end{array}$ & gr/dscf & $\begin{array}{c}\text { Efficiency, } \\
\% \\
\end{array}$ \\
\hline 1 & $2 / 9 / 00$ & 318 & 189,207 & 2.0592 & 323 & 151,234 & 0.0171 & 99.17 \\
\hline 2 & $2 / 9 / 00$ & 314 & 187,190 & 1.2795 & 316 & 151,062 & 0.0437 & 96.58 \\
\hline 3 & $2 / 9 / 00$ & 323 & 190,633 & 1.5050 & 324 & 151,894 & 0.0153 & 98.98 \\
\hline \multicolumn{2}{|c|}{ Average } & 318 & 189,010 & 1.6146 & 321 & 151,397 & 0.0254 & 98.24 \\
\hline
\end{tabular}

Table 4. Particulate Collection Efficiency During Mercury Sampling ${ }^{\mathrm{a}}$

\begin{tabular}{llcc|cccc}
\hline & \multicolumn{3}{c}{ Location: ESP Inlet } & \multicolumn{4}{c}{$\begin{array}{c}\text { Location: ESP Outlet } \\
\text { (across both Fields 1 and 2) }\end{array}$} \\
\cline { 2 - 7 } Fuel & $\begin{array}{c}\text { Temp, } \\
{ }^{\circ} \mathbf{F}\end{array}$ & $\begin{array}{c}\text { Gas Volume, } \\
\text { dscfm }\end{array}$ & gr/dscf & $\begin{array}{c}\text { Temp, } \\
{ }^{\circ} \mathbf{F}\end{array}$ & $\begin{array}{c}\text { Gas Volume, } \\
\text { dscfm }\end{array}$ & \multicolumn{3}{c}{ gr/dscf } & $\begin{array}{c}\text { Efficiency, } \\
\text { \% }\end{array}$ \\
\hline Coal & 319 & 172,026 & 1.6664 & 288 & 137,869 & 0.0043 & 99.74 \\
Paper & 310 & 170,134 & 1.4993 & 293 & 135,562 & 0.0092 & 99.39 \\
Plastic & 319 & 171,686 & 1.3544 & 267 & 137,454 & 0.0055 & 99.60 \\
Blend & 294 & 178,551 & 1.5347 & 290 & 143,294 & 0.0086 & 99.44 \\
\hline
\end{tabular}

${ }^{a}$ Not regulatory measurements. 
At both the inlet and outlet sampling location, the flue gas temperature was above the minimum filter temperature $\left(248^{\circ} \mathrm{F}\right)$ as stated by the $\mathrm{OH}$ method. The temperatures at the inlet to the ESP ranged from $294^{\circ}$ to $319^{\circ} \mathrm{F}$ and $267^{\circ}$ to $293^{\circ} \mathrm{F}$ at the stack. Consequently, EPA Method 17 sampling procedures (in-stack filtration) were used at both locations.

In an effort to substantiate the flue gas mercury data, coal and PDF feed, mechanical collector hopper ash, and ESP hopper ash were sampled during each test period. These samples were analyzed for total mercury and, along with the flue gas emissions data, were used to calculate the mercury mass balances. Analyses completed on the coal, plastic, and paper were ultimate, proximate, Btu, chlorides, and mercury analyses.

\subsection{Process Operation During Testing}

Tables 5-9 summarize the process operating conditions and gas emissions during the mercury speciation test program for Unit 9. The attempt was to maintain the plant at approximately $80 \%$ full load (40 MW) during the entire project. According to plant personnel, this was done. CEM results shown in the tables are very representative of the normal daily operation of the plant. The only operation problem that occurred was that the plastic feeder needed to be fixed prior to completing the blend test. Therefore, this test was completed following the coal with paper tests. It should be noted that the gas flow rate measured by the plant shows a substantial decrease $(\sim 25 \%)$ across the unit. Because Unit 9 is under positive pressure, this indicates a relatively large leak somewhere in the system.

Table 5. Blount Station Unit 9 Operating Conditions Summary, Coal Only

\begin{tabular}{lccc}
\hline Run & $\mathbf{1}$ & $\mathbf{2}$ & $\mathbf{3}$ \\
\hline Process Conditions & & & \\
Coal Feed Rate, $\mathrm{lb} / \mathrm{hr}$ & 43,478 & 43,478 & 43,480 \\
Plastic Feed Rate, $\mathrm{lb} / \mathrm{hr}$ & - & - & - \\
Paper Feed Rate, $\mathrm{lb} / \mathrm{hr}$ & - & - & - \\
Gas Flow at the Exit, kscfm & 149.3 & 151.8 & 144.0 \\
ESP Inlet Gas Temperature, ${ }^{\circ} \mathrm{F}$ & 316 & 326 & 317 \\
ESP Outlet Gas Temperature, ${ }^{\circ} \mathrm{F}$ & 278 & 308 & 277 \\
Flue Gas Data & & & \\
Stack $\mathrm{O}_{2}, \%$ & 9.3 & 9.2 & 8.5 \\
Exit $\mathrm{CO}_{2}, \%$ & 10.1 & 10.1 & 10.5 \\
Exit $\mathrm{NO}_{x}, \mathrm{lb} / 10^{6}$ Btu & 0.50 & 0.46 & 0.47 \\
${\text { Exit } \mathrm{SO}_{2} \text { Emissions, lb/10 }}^{6} \mathrm{Btu}$ & 2.43 & 2.52 & 2.54 \\
Flue $\mathrm{Gas} \mathrm{Moisture} \mathrm{at} \mathrm{Stack,} \%$ & 6.8 & 7.1 & 7.3 \\
\hline
\end{tabular}


Table 6. Blount Station Unit 9 Operating Conditions Summary, Coal and Paper

\begin{tabular}{|c|c|c|c|c|}
\hline Run & 1 & 2 & 3 & 4 \\
\hline \multicolumn{5}{|l|}{ Process Conditions } \\
\hline Coal Feed Rate, lb/hr & 36,261 & 36,783 & 34,783 & 37,217 \\
\hline Plastic Feed Rate, lb/hr & - & - & - & - \\
\hline Paper Feed Rate, lb/hr & 9800 & 9278 & 10,845 & 9278 \\
\hline Gas Flow at the Exit, kscfm & 144.1 & 148.3 & 145.5 & 146.8 \\
\hline ESP Inlet Gas Temperature, ${ }^{\circ} \mathrm{F}$ & 310 & 310 & 310 & 310 \\
\hline ESP Outlet Gas Temperature, ${ }^{\circ} \mathrm{F}$ & 270 & 297 & 295 & 308 \\
\hline \multicolumn{5}{|l|}{ Flue Gas Data } \\
\hline Stack $\mathrm{O}_{2}, \%$ & 7.6 & 8.6 & 8.9 & 9.1 \\
\hline Exit $\mathrm{CO}_{2}, \%$ & 10.4 & 10.7 & 10.7 & 10.7 \\
\hline Exit $\mathrm{NO}_{\mathrm{x}}$ Emissions, $\mathrm{lb} / 10^{6} \mathrm{Btu}$ & 0.49 & 0.45 & 0.45 & 0.45 \\
\hline Exit $\mathrm{SO}_{2}$ Emissions, $\mathrm{lb} / 10^{6} \mathrm{Btu}$ & 1.76 & 1.78 & 1.82 & 1.96 \\
\hline Flue Gas Moisture at Stack, \% & 6.6 & 8.6 & 7.1 & 6.9 \\
\hline
\end{tabular}

Table 7. Blount Station Unit 9 Operating Conditions Summary, Coal and Plastic

\begin{tabular}{|c|c|c|c|c|}
\hline Run & 1 & 2 & 3 & 4 \\
\hline \multicolumn{5}{|l|}{ Process Conditions } \\
\hline Coal Feed Rate, lb/hr & 35,217 & 33,043 & 34,783 & 34,348 \\
\hline Plastic Feed Rate, lb/hr & 6195 & 6928 & 6458 & 6517 \\
\hline Paper Feed Rate, $\mathrm{lb} / \mathrm{hr}$ & - & - & - & - \\
\hline Gas Flow at the Exit, kscfm & 144.9 & 150.5 & 147.1 & 151.3 \\
\hline ESP Inlet Gas Temperature, ${ }^{\circ} \mathrm{F}$ & 309 & 311 & 322 & 333 \\
\hline ESP Outlet Gas Temperature, ${ }^{\circ} \mathrm{F}$ & 283 & 261 & 258 & 265 \\
\hline \multicolumn{5}{|l|}{ Flue Gas Data } \\
\hline Stack $\mathrm{O}_{2}, \%$ & 8.6 & 9.0 & 8.9 & 9.2 \\
\hline Exit $\mathrm{CO}_{2}, \%$ & 10.2 & 10.0 & 9.9 & 9.6 \\
\hline Exit $\mathrm{NO}_{\mathrm{x}}$ Emissions, $\mathrm{lb} / 10^{6} \mathrm{Btu}$ & 0.51 & 0.46 & 0.50 & 0.59 \\
\hline Exit $\mathrm{SO}_{2}$ Emissions, $\mathrm{lb} / 10^{6} \mathrm{Btu}$ & 1.93 & 1.72 & 1.79 & 1.81 \\
\hline Flue Gas Moisture at Stack, \% & 7.5 & 7.4 & 7.1 & 7.6 \\
\hline
\end{tabular}


Table 8. Blount Station Unit 9 Operating Conditions Summary, Blend

\begin{tabular}{|c|c|c|c|c|}
\hline Run & 1 & 2 & 3 & 4 \\
\hline \multicolumn{5}{|l|}{ Process Conditions } \\
\hline Coal Feed Rate, lb/hr & 35,217 & 35,217 & 32,174 & 30,435 \\
\hline Plastic Feed Rate, lb/hr & 3750 & 3750 & 4638 & 4521 \\
\hline Paper Feed Rate, lb/hr & 3750 & 3750 & 5181 & 5181 \\
\hline Gas Flow at the Exit, kscfm & 144.9 & 150.5 & 147.1 & 151.3 \\
\hline ESP Inlet Gas Temperature, ${ }^{\circ} \mathrm{F}$ & 310 & 311 & 321 & 327 \\
\hline ESP Outlet Gas Temperature, ${ }^{\circ} \mathrm{F}$ & 285 & 276 & 299 & 301 \\
\hline \multicolumn{5}{|l|}{ Flue Gas Data } \\
\hline Stack $\mathrm{O}_{2}, \%$ & $\mathrm{NA}^{\mathrm{a}}$ & NA & 8.0 & 8.6 \\
\hline Exit $\mathrm{CO}_{2}, \%$ & 9.7 & 9.7 & 10.3 & 10.1 \\
\hline Exit $\mathrm{NO}_{\mathrm{x}}, \mathrm{lb} / 10^{6} \mathrm{Btu}$ & 0.50 & 0.53 & 0.45 & 0.44 \\
\hline Exit $\mathrm{SO}_{2}$ Emissions, $\mathrm{lb} / 10^{6} \mathrm{Btu}$ & 1.67 & 1.93 & 2.06 & 1.75 \\
\hline Flue Gas Moisture at Stack, \% & 6.9 & 6.1 & 7.0 & 7.5 \\
\hline
\end{tabular}

${ }^{\text {a }}$ Data are not available.

Table 9. Sample Train Components - EPA Method 17 Configuration

\begin{tabular}{|c|c|}
\hline Component & Details \\
\hline Nozzle & Quartz \\
\hline Filter & Quartz, in glass \\
\hline Probe & Quartz heated to a minimum temperature of $120^{\circ} \mathrm{C}$ \\
\hline Connector Line & $\begin{array}{l}\text { Teflon line used to connect from probe to impingers - heated to a } \\
\text { minimum of } 120^{\circ} \mathrm{C}\end{array}$ \\
\hline Impingers 1 and 2 & $1 \mathrm{~N} \mathrm{KCl}$ solution; modified Smith Greenburg (SG) impinger \\
\hline Impinger 3 & $1 \mathrm{~N} \mathrm{KCl}$ solution; standard SG impinger \\
\hline Impinger 4 & $5 \%$ nitric acid-10\% hydrogen peroxide; modified SG impinger \\
\hline Impingers 5 and 6 & $10 \%$ sulfuric acid $-4 \%$ potassium permanganate; modified SG impinger \\
\hline Impinger 7 & $10 \%$ sulfuric acid $-4 \%$ potassium permanganate; standard SG impinger \\
\hline Impinger 8 & Silica gel; modified SG impinger \\
\hline
\end{tabular}

\subsection{FLUE GAS SAMPLING AND ANALYTICAL METHODS}

This section describes the methods and analytical procedures that were used for this test program to determine the mercury speciation and chlorides in the flue gas, as well as the total mercury in the solid streams of the plant. The details of all the EPA sampling procedures discussed in this section (EPA Methods 1-4, 5, 17, 26A, and the OH method) can be found on EPA's Emission Measurement Center Web site at http://www.epa.gov/ttn/emc. 


\subsection{Ontario Hydro Mercury Speciation Method}

The mercury speciation method used to conduct this project is entitled "Standard Test Method for Elemental, Oxidized, Particle-Bound, and Total Mercury in Flue Gas Generated from Coal-Fired Stationary Sources (Ontario Hydro Mercury Speciation Method)." This method was developed jointly by Dr. Keith Curtis and the Energy \& Environmental Research Center (EERC). It was subsequently validated by the EERC at both the pilot- and full-scale level $(3,4)$. The method is currently being reviewed by American Society for Testing and Materials (ASTM) Subcommittee D22.03.01 and was the mercury speciation method required for EPA's Information Collection Request.

In the $\mathrm{OH}$ method, using the sampling procedures outlined in EPA Methods 1-4 and EPA Method 17 or Method 5, a sample is withdrawn from the flue gas stream isokinetically through the filtration system, which is followed by a series of impingers in an ice bath. Particulate-bound mercury is collected on the front half and filter; oxidized mercury $\left(\mathrm{Hg}^{2+}\right)$ is collected in impingers containing $1 \mathrm{~N}$ potassium chloride $(\mathrm{KCl})$ solution; and elemental mercury $\left(\mathrm{Hg}^{0}\right)$ is collected in one impinger containing a $5 \% \mathrm{v} / \mathrm{v}$ nitric acid $\left(\mathrm{HNO}_{3}\right)$ and $10 \% \mathrm{v} / \mathrm{v}$ hydrogen peroxide $\left(\mathrm{H}_{2} \mathrm{O}_{2}\right)$ solution and in three impingers containing a solution of $10 \% \mathrm{v} / \mathrm{v}$ sulfuric acid $\left(\mathrm{H}_{2} \mathrm{SO}_{4}\right)$ and $4 \% \mathrm{w} / \mathrm{v}$ potassium permanganate $\left(\mathrm{KMnO}_{4}\right)$. An impinger containing silica gel collects any remaining moisture. Quartz fiber filters were used as the filter media for the testing, and the filter holder was glass. A heated Teflon line connected the probe and impinger train. A target sampling time of $2 \mathrm{hr}$ was used, with a target sample volume of 1 to 2.5 standard cubic meters. A schematic of the sample train and the recovery procedures is shown in Figures 2 and 3. Table 9 presents a list of sample train components for the EPA Method 17 configuration.

All glassware for the sample trains was precleaned using a 4-hr soak in a $10 \% \mathrm{v} / \mathrm{v} \mathrm{HNO}_{3}$ solution, with no impinger glassware used more than once during the field test. Samples collected using the $\mathrm{OH}$ method were recovered into the following fractions:

- Container 1 - the sample filter

- Container 2 - the front half rinse (includes all surfaces upstream of the filter)

- Container 3 - Impingers 1 through 3 ( $\mathrm{KCl}$ impingers) and rinses

- Container 4 - Impinger $4\left(\mathrm{HNO}_{3}-\mathrm{H}_{2} \mathrm{O}_{2}\right.$ impinger $)$ and rinses

- Container 5 - Impingers 5 through $7\left(\mathrm{H}_{2} \mathrm{SO}_{4}-\mathrm{KMnO}_{4}\right.$ impingers $)$ and rinse

- Silica gel - Impinger 8 (silica gel impinger). Note that this sample is weighed for moisture determination and is not included in the mercury analysis.

The sample fractions were prepared for analyses as specified in the method. It should be noted that these preparation steps are the most difficult aspect of the $\mathrm{OH}$ method and the most likely source of error. This is discussed in more detail in Section 5, Quality Assurance/Quality Control. 


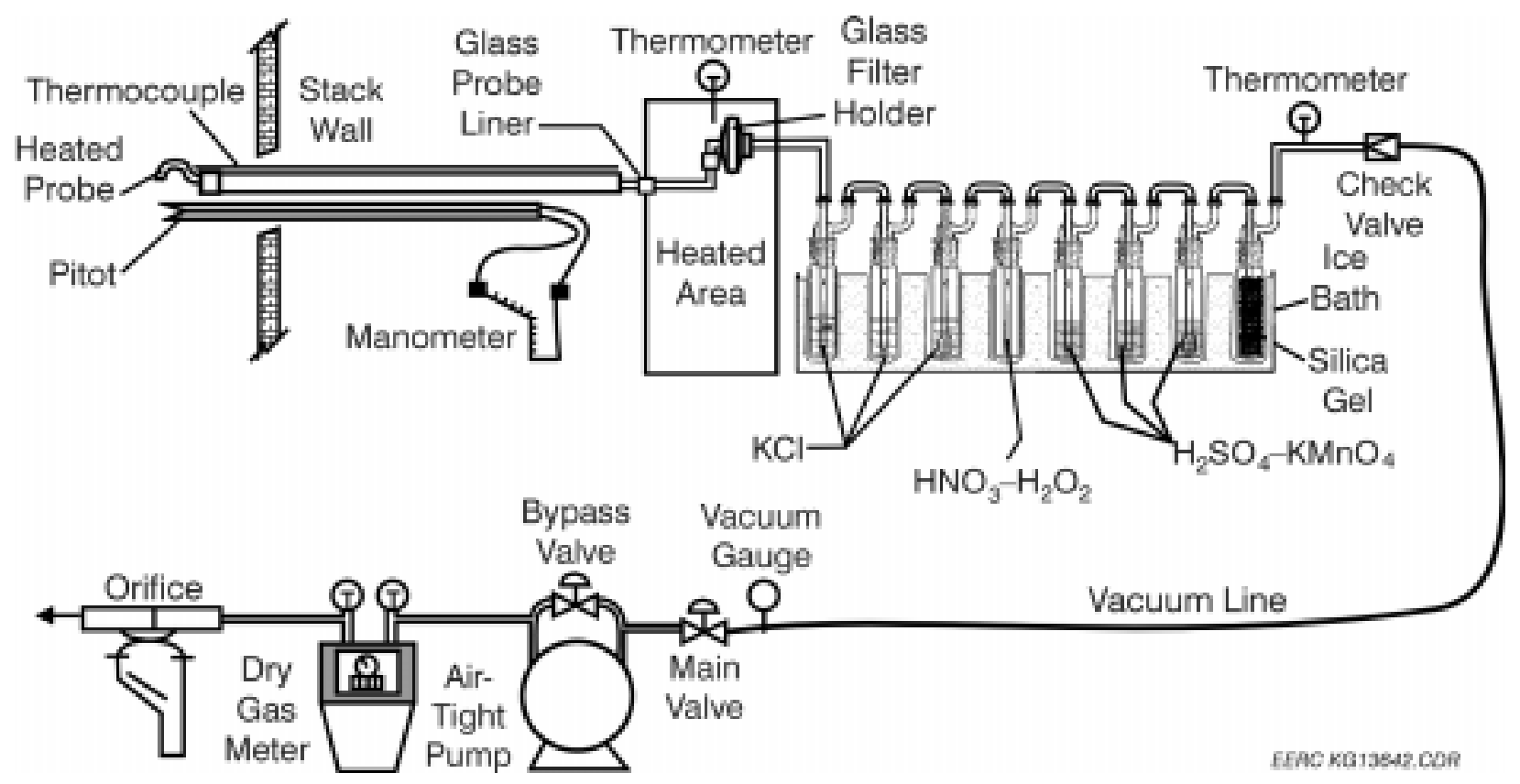

Figure 2. Schematic of the sampling train.

1. Rinse filter holder and connector with $0.1 \mathrm{~N} \mathrm{HNO}_{3}$.

2. Add $5 \% \mathrm{w} / \mathrm{KMnO}_{4}$ to each impinger bottle until purple color remains.

3. Rinse with $10 \% \%_{4}, \mathrm{HNO}_{3}$.

4. Rinse with a very small amount of $10 \% \mathrm{w} / \mathrm{v} \quad$ Rinse Bottles Sparingly with

$\mathrm{NH}_{2} \mathrm{OH} \cdot \mathrm{H}_{2} \mathrm{SO}_{4}$ if brown residue remains. $\quad-0.1 \mathrm{~N} \mathrm{HNO}$

5. Final rinse with $10 \% \mathrm{~V} / \mathrm{V} \mathrm{HNO}_{3}$. $-10 \% \mathrm{w} / \mathrm{N} \mathrm{NH}_{2} \mathrm{OH} \cdot \mathrm{H}_{2} \mathrm{SO}_{4}$

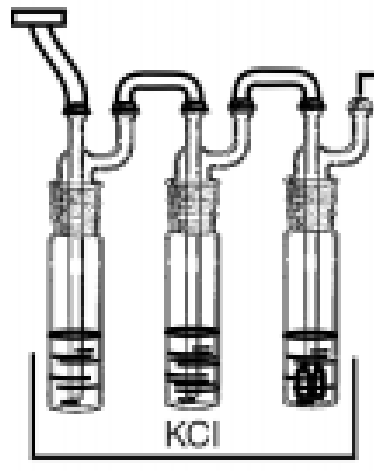

Rinse with $0.1 \mathrm{NHNO}_{3}-0.1 \mathrm{~N} \mathrm{HNO}_{3}$

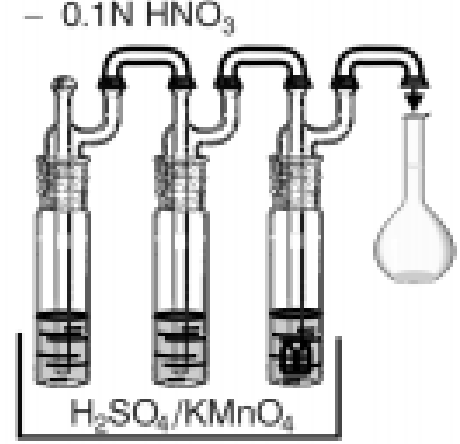

Rinse All U-Tubes with $0.1 \mathrm{~N} \mathrm{HNO}_{3}$

renC D. 35130 CON

Figure 3. Sample recovery scheme for the mercury speciation sampling train. 
After each fraction had been prepared, mercury analysis was accomplished by CVAAS (coldvapor atomic absorption spectroscopy). CVAAS is a method based on the absorption of radiation at $253.7 \mathrm{~nm}$ by mercury vapor. The mercury is reduced to the elemental state and aerated from solution in a closed system. The mercury vapor passes through a cell positioned in the light path of an atomic absorption spectrometer. Mercury concentration is proportional to the resulting absorbance. A soda-lime trap and a magnesium perchlorate trap were used to precondition the gas before it entered the absorption cell. For all the $\mathrm{OH}$ mercury samples (except the filter), the analyses were done on-site.

\subsection{EPA Method 26A}

To measure concentration of chlorides in the flue gas, EPA Method 26A was used. A schematic of the train is shown in Figure 4. This method was designed to measure both the $\mathrm{HCl}$ and $\mathrm{Cl}_{2}$ concentrations in the flue gas. During the sampling, the separation of the halides $(\mathrm{HCl})$ from the halogens $\left(\mathrm{Cl}_{2}\right)$ is accomplished physically within the impinger matrices. $\mathrm{Cl}_{2}$ exhibits a low solubility in acid solutions $\left(0.1 \mathrm{~N} \mathrm{H}_{2} \mathrm{SO}_{4}\right)$, but is collected effectively in basic solutions $(0.1 \mathrm{~N} \mathrm{NaOH})$. The $\mathrm{HCl}$, on the other hand, is captured effectively by the $0.1 \mathrm{~N} \mathrm{H}_{2} \mathrm{SO}_{4}$ solution. The impinger train is operated similarly to other sampling procedures such as EPA Method 5 or EPA Method 29. These samples are then analyzed using ion chromatography techniques. Since the gaseous-phase chlorides are not impacted by gas flow or isokinetic sampling rate, the sampling was operated at a constant flow from a single traverse point. It has been found that in the presence of $\mathrm{SO}_{2}$ the method does not accurately speciate chlorides (5); however, the method still gives an accurate measurement of total chlorides. Once the chlorides were collected in the solutions, they were analyzed using ion chromatography techniques.

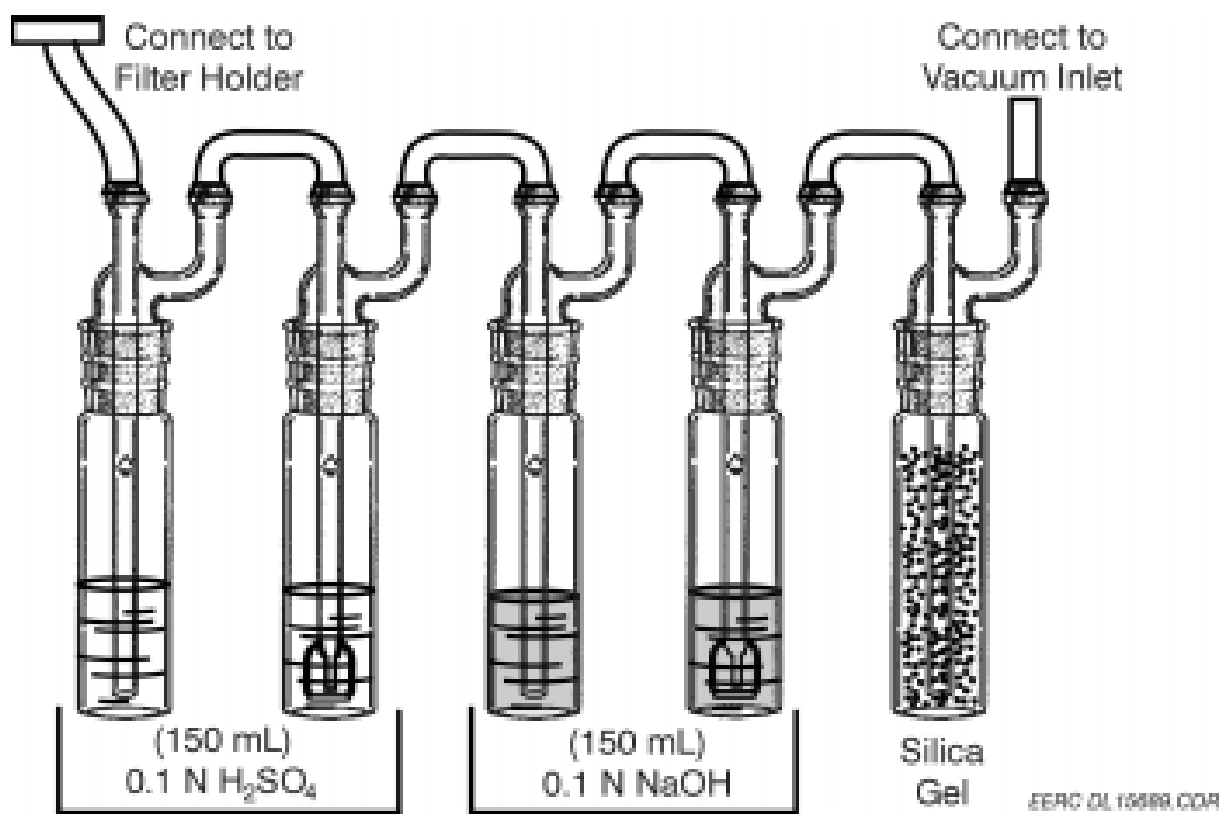

Figure 4. A schematic of the EPA Method 26A impinger train that was used for chloride measurement. 


\subsection{Determination of Coal and Ash Mercury}

Mercury in coal was determined by digesting the coal with $\mathrm{HNO}_{3}$ and $\mathrm{HCl}$ in sealed highpressure Teflon digestion vessels similar to EPA Method SW846 3051, Microwave Assisted Acid Digestion of Sediments, Sludges, Soils, and Oils. The modifications to the method include 1) the use of larger, high-pressure Teflon vessels, designed specifically for coal; 2) the use of nitric and hydrochloric acid for digestion; and 3) the use of multiple cooldown and venting steps to completely digest the coal. The digested samples were analyzed by CVAAS according to EPA Method 7471A. All values were reported as $\mu \mathrm{g} / \mathrm{g} \mathrm{Hg}$ on a dry coal basis.

Mercury in the hopper ashes was determined using EPA Method 7473. Mercury in the $\mathrm{OH}$ filter samples was determined using a modified EPA Method SW846 3051. In this case, the modifications include the use of $\mathrm{HF}, \mathrm{HNO}_{3}, \mathrm{HCl}$, and boric acid and a tenfold reduction in the volumes of reagents and sample used to reduce waste. This reduction in reagent volume is acceptable because modern dedicated mercury analyzers do not require the large volumes that previous manual methods required. The digested samples were analyzed by CVAAS according to EPA Method 7471 A. All values were reported as $\mu \mathrm{g} / \mathrm{g}$ mercury.

\subsection{Auxiliary Flue Gas Measurements}

EPA methods for auxiliary flue gas measurements included flue gas flow rate using EPA Methods 1 and 2 (pitot traverse). To determine the $\mathrm{O}_{2}$ levels at each sample location, a portable EcoAmerica $\mathrm{O}_{2}$ analyzer using a paramagnetic cell was used. This portable $\mathrm{O}_{2}$ analyzer's linearity was verified using EPA Protocol 1 certified gas standards. For the purposes of this report, the mercury concentrations are reported on a constant $-\mathrm{O}_{2}$ basis $\left(3 \% \mathrm{O}_{2}\right)$. The flue gas moisture was measured using EPA Method 4 (condensation/gravimetric analysis). All these measurements were collected as integral parts of the mercury speciation test runs at all sampling locations. This analyzer was also used to measure the $\mathrm{CO}_{2}, \mathrm{NO}_{\mathrm{x}}$, and $\mathrm{SO}_{2}$ concentrations at each sample point.

\subsection{Mercury CEMs}

Concurrently with the $\mathrm{OH}$ method sampling, two different mercury CEMs, the Semtech $\mathrm{Hg}$ 2010 and the Tekran Model 2537A, were used to obtain gas-phase mercury concentration data at the stack location. A brief description of each instrument is provided below. The flue gas was converted and conditioned with a separate unit, and the conditioned dry gas was then analyzed using the CEMs.

\subsubsection{Semtech $\mathrm{Hg} 2010$}

The commercial Semtech Hg 2010 mercury analyzer (Semtech Metallurgy AB, Lund, Sweden) is essentially a portable Zeeman-modulated CVAAS instrument that can monitor $\mathrm{Hg}^{0}$ continuously. The flue gas was converted and conditioned with a separate unit, and the conditioned dry gas was then analyzed using the Semtech $\mathrm{Hg} 2010$ analyzer. The analyzer uses Zeeman effect background correction by applying a modulated magnetic field to a mercury lamp to minimize interferences from the presence of $\mathrm{SO}_{2}$, hydrocarbons, and fine particulate in the flue gas sample. The operating range of the analyzer is $0.3 \mu \mathrm{g} / \mathrm{Nm}^{3}$ to $20 \mathrm{mg} / \mathrm{Nm}^{3} \mathrm{Hg}^{0}$, as specified by Semtech Metallurgy AB. The 
Semtech $\mathrm{Hg} 2010$ has also been certified by TUEV Rheinland for determining compliance with the German legal limit of $50 \mu \mathrm{g} / \mathrm{Nm}^{3}$ for total mercury from waste incinerators.

\subsubsection{Tekran Model 2537A}

The Tekran mercury CEM has been the standard instrument for measuring ambient mercury concentrations for the past 10 years. With the development of a pretreatment/conversion system by the EERC, the instrument was used to measure mercury flue gas concentrations at the Blount Station. The analyzer is based on the principle of atomic fluorescence, which provides an inherently more sensitive signal than atomic adsorption. The instrument has a detection limit of $0.1 \mathrm{ng} / \mathrm{m}^{3}$, with a maximum limit of about $100 \mu \mathrm{g} / \mathrm{m}^{3}$. The instrument collects the mercury on a gold trap which reconcentrates the mercury and separates it from potential interferences.

Although the measurement is a batch process using a dual-gold cartridge design, the instrument can provide mercury data in approximately 2.5 minutes. This is done by collecting mercury on one trap while the mercury from the second trap is being desorbed at approximately $500^{\circ} \mathrm{C}$ into the detector. The gold trap is rapidly cooled by passing argon over it.

An internal elemental mercury permeation source is used to calibrate the instrument. This is done daily. It can also be calibrated manually using standard gastight syringes.

\subsection{MERCURY RESULTS}

\subsection{Fuel Analysis Data}

Representative samples of each of the fuels (coal, paper, and plastic) were collected and analyzed for mercury and chlorine as well as a proximate/ultimate analysis. The results of these analyses are shown in Table 10. The fuel firing rates and calculated flow rates are shown in Table 11. All the mass flow rates were calculated based on the total heating rate needed to provide $40 \mathrm{MW}$. The plant provided the input heating rate of the coal, plastic, and paper. With the known heating values (Table 10), the mass flow rates were calculated. Based on a weighted average, the mass flow rates, and the measured analyses of each of the fuels shown in Table 10, a composite fuel analysis for each run was calculated and is shown in Table 12.

\subsection{ESP Ash and Sample Filter Mercury}

During testing, ash samples were collected from the dust bin (cyclone) and from the ESP hoppers. These samples were analyzed for total mercury content. ESP hopper ash was collected concurrently with the $\mathrm{OH}$ runs for verification of the particulate mercury concentrations. The results of these analyses along with the comparative $\mathrm{OH}$ data are shown in Table 13. There is reasonable agreement between the mercury concentration in the ESP hopper ash and the mercury concentration on the filter used to measure the flue gas mercury concentration at the inlet to the ESP. As would be expected, the mercury concentration is somewhat higher on the filter compared to the ESP hopper ash because of the better contacting surface. Also, the increasing mercury concentration with decreasing particle size indicates the importance of surface area in mercury sorption. 
Table 10. Fuel Analysis ${ }^{a}$

\begin{tabular}{lccccc}
\hline Fuel & Coal & Plastic & Silver Paper & Yellow & Avg. Paper \\
\hline Mercury, ppm (dry) & 0.0339 & $<0.005$ & $<0.005$ & $<0.005$ & $<0.005$ \\
Chlorine, ppm (dry) & 140 & 6160 & 620 & 520 & 570 \\
Proximate Analysis, wt\% & & & & \\
Moisture & 12.40 & 0.6 & 3.5 & 5 & 4.25 \\
Volatile Matter & 33.86 & 97.49 & 90.29 & 92.05 & 91.17 \\
Fixed Carbon & 44.01 & 0.32 & 1.27 & 1.49 & 1.38 \\
Ash & 9.72 & 1.59 & 4.94 & 1.45 & 3.195 \\
Ultimate Analysis, wt\% & & & & & \\
Hydrogen & 5.63 & 11.83 & 6.66 & 7.57 & 7.115 \\
Carbon & 63.65 & 74.44 & 43.17 & 46.51 & 44.84 \\
Nitrogen & 1.83 & 2.3 & 0.56 & 0.6 & 0.58 \\
Sulfur & 1.37 & 0.36 & 0.14 & 0.16 & 0.15 \\
Oxygen & 17.36 & 9.48 & 44.53 & 43.71 & 44.12 \\
Heating Value, Btu/lb & 10,907 & 17,033 & 7765 & 8833 & 8299 \\
\hline a As-received unless otherwise noted & & & & &
\end{tabular}

${ }^{a}$ As-received unless otherwise noted.

Table 11. Fuel Flow Rates

\begin{tabular}{lc|cccc|ccc}
\hline Run & $\begin{array}{c}\text { Btu/lb } \\
\text { (calculated) }\end{array}$ & \multicolumn{4}{c|}{$\begin{array}{c}\text { lb/hr } \\
\text { (calculated) }\end{array}$} & \multicolumn{3}{c}{$\begin{array}{c}\mathbf{1 0}^{6} \text { Btu/hr } \\
\text { (provided by plant) }\end{array}$} \\
\cline { 2 - 10 } No. & Total & Total & Coal & Plastic & Paper & Coal & Plastic & Paper \\
\hline D1-1 & 11,203 & 44,631 & 37,131 & 3750 & 3750 & 405 & 64 & 31 \\
D1-2 & 11,203 & 44,631 & 37,131 & 3750 & 3750 & 405 & 64 & 31 \\
D2-1 & 10,375 & 48,032 & 38,231 & - & 9800 & 417 & - & 81 \\
D2-2 & 10,404 & 48,059 & 38,781 & - & 9278 & 423 & - & 77 \\
D3-1 & 10,312 & 47,517 & 36,673 & - & 10,845 & 400 & - & 90 \\
D3-2 & 10,409 & 48,518 & 39,240 & - & 9278 & 428 & - & 77 \\
D4-1 & 11,248 & 43,742 & 33,922 & 4638 & 5181 & 370 & 79 & 43 \\
D4-2 & 11,247 & 41,790 & 32,089 & 4521 & 5181 & 350 & 77 & 43 \\
D5-1 & 10,907 & 45,841 & 45,841 & - & - & 500 & - & - \\
D5-2 & 10,907 & 45,841 & 45,841 & - & - & 500 & - & - \\
D6-1 & 10,907 & 45,841 & 45,841 & - & - & 500 & - & - \\
D7-1 & 11,780 & 43,295 & 37,131 & 6165 & - & 405 & 105 & - \\
D7-2 & 11,923 & 41,767 & 34,839 & 6928 & - & 380 & 118 & - \\
D8-1 & 11,825 & 43,131 & 36,673 & 6458 & - & 400 & 110 & - \\
D8-2 & 11,842 & 42,731 & 36,214 & 6517 & - & 395 & 111 & - \\
\hline
\end{tabular}


Table 12. Composite Fuel Analysis, Calculated

\begin{tabular}{|c|c|c|c|c|c|c|c|c|c|c|c|c|c|}
\hline \multirow[b]{2}{*}{ Sample No.: } & \multirow{2}{*}{\begin{tabular}{c|} 
Coal \\
$1-3$ \\
\end{tabular}} & \multicolumn{4}{|c|}{ Coal plus Paper } & \multicolumn{4}{|c|}{ Coal plus Plastic } & \multicolumn{4}{|c|}{ Blend } \\
\hline & & 1 & 2 & 3 & 4 & 1 & 2 & 3 & 4 & 1 & 2 & 3 & 4 \\
\hline Mercury, $\mu \mathrm{g} / \mathrm{g}$ (dry) & 0.0339 & 0.0267 & 0.0271 & 0.0258 & 0.0271 & 0.0289 & 0.0280 & 0.0286 & 0.0285 & 0.0260 & 0.0260 & 0.0261 & 0.0259 \\
\hline Chlorine, $\mu \mathrm{g} / \mathrm{g}$ (dry) & 140 & 231 & 227 & 242 & 226 & 1037 & 1183 & 1083 & 1100 & 894 & 894 & 883 & 906 \\
\hline \multicolumn{14}{|c|}{ Proximate Analysis, wt\% } \\
\hline Moisture & 12.40 & 10.67 & 10.76 & 10.46 & 10.77 & 10.64 & 10.35 & 10.55 & 10.52 & 10.07 & 10.07 & 10.10 & 10.03 \\
\hline Volatile Matter & 33.86 & 46.05 & 45.40 & 47.48 & 45.30 & 43.34 & 44.89 & 43.82 & 44.01 & 48.00 & 48.00 & 47.79 & 48.22 \\
\hline Fixed Carbon & 44.01 & 34.94 & 35.42 & 33.88 & 35.50 & 37.50 & 36.44 & 37.17 & 37.04 & 33.92 & 33.92 & 34.07 & 33.76 \\
\hline Ash, $\%$ & 9.72 & 8.33 & 8.41 & 8.17 & 8.42 & 8.51 & 8.31 & 8.45 & 8.42 & 8.01 & 8.01 & 8.03 & 7.98 \\
\hline \multicolumn{14}{|l|}{ Ultimate Analysis, wt $\%$} \\
\hline Hydrogen & 5.63 & 5.95 & 5.93 & 5.98 & 5.93 & 6.55 & 6.70 & 6.60 & 6.62 & 6.53 & 6.53 & 6.52 & 6.54 \\
\hline Carbon & 63.65 & 59.65 & 59.86 & 59.18 & 59.90 & 65.26 & 65.52 & 65.34 & 65.37 & 62.71 & 62.71 & 62.73 & 62.70 \\
\hline Nitrogen & 1.83 & 1.56 & 1.58 & 1.53 & 1.58 & 1.90 & 1.91 & 1.90 & 1.90 & 1.74 & 1.74 & 1.74 & 1.74 \\
\hline Sulfur & 1.37 & 1.11 & 1.12 & 1.08 & 1.12 & 1.22 & 1.19 & 1.21 & 1.21 & 1.11 & 1.11 & 1.11 & 1.10 \\
\hline Oxygen & 17.36 & 23.05 & 22.75 & 23.72 & 22.70 & 16.19 & 15.99 & 16.13 & 16.10 & 19.57 & 19.57 & 19.53 & 19.60 \\
\hline Heating Value, Btu/lb & 10,907 & 10,352 & 10,382 & 10,287 & 10,387 & 11,820 & 11,969 & 11,867 & 11,884 & 11,319 & 11,319 & 11,313 & 11,325 \\
\hline $\begin{array}{l}\mathrm{Hg} \text { from Fuel, } \\
\mathrm{lb} / 10^{12} \mathrm{Btu}\end{array}$ & 3.55 & 2.89 & 2.92 & 2.81 & 2.93 & 2.73 & 2.61 & 2.69 & 2.68 & 2.55 & 2.55 & 2.57 & 2.54 \\
\hline
\end{tabular}


Table 13. Particulate Mercury

\begin{tabular}{lc|cccc}
\hline & & \multicolumn{4}{|c}{ Fly Ash Mercury Concentration, $\boldsymbol{\mu g} / \mathbf{g}$} \\
Run & Fuel & Dust Bin & ESP Field 1 & ESP Field 2 & OH Inlet \\
\hline D1-1 & Blend & 0.0422 & 0.277 & 0.439 & 0.428 \\
D1-2 & Blend & 0.0463 & 0.206 & 0.468 & 0.452 \\
D2-1 & Coal and paper & 0.0539 & 0.334 & 0.567 & 0.467 \\
D2-2 & Coal and paper & 0.0530 & 0.306 & 0.587 & 0.480 \\
D3-1 & Coal and paper & 0.0624 & 0.299 & 0.463 & 0.574 \\
D3-2 & Coal and paper & 0.0520 & 0.650 & 0.647 & 0.639 \\
D4-1 & Blend & 0.0457 & 0.308 & 0.776 & NA \\
D4-2 & Blend & 0.0583 & 0.253 & 0.565 & 0.648 \\
D5-1 & Coal & 0.0519 & 0.314 & 0.591 & 0.362 \\
D5-2 & Coal & 0.0615 & 0.304 & 0.534 & 0.572 \\
D6-1 & Coal & 0.0708 & 0.396 & 0.600 & 0.757 \\
D7-1 & Coal and plastic & 0.0559 & 0.369 & 0.644 & 0.492 \\
D7-2 & Coal and plastic & 0.0599 & 0.358 & 0.501 & 0.589 \\
D8-1 & Coal and plastic & 0.0540 & 0.349 & 0.658 & 0.474 \\
D8-2 & Coal and plastic & 0.0358 & 0.403 & 0.529 & 0.292 \\
\hline
\end{tabular}

The mercury was also measured on the filters at the outlet of the ESP. Because of the high particulate collection efficiency of the ESP, the concentration of particulate-bound mercury measured at the outlet of the ESP was very low $\left(<0.04 \mu \mathrm{g} / \mathrm{Nm}^{3}\right)$.

\subsection{Mercury Speciation Results}

This section presents the flue gas mercury speciation results across the ESP for each of the four fuel conditions. These results are shown in Tables $14-17$. All data are based on $68^{\circ} \mathrm{F}$, dry conditions, and adjusted to $3 \%$ oxygen. Figures 5-8 show the mercury removal across the ESP. The original data sheets for the flue gas mercury are included in the appendices, available as a separate volume upon request. Examples of the calculations used in this report are also available in the Appendices. All the mercury data were averaged, and a standard deviation was calculated. As can be seen from the tables, the data variability was low.

The speciation of mercury at the stack is important because $\mathrm{Hg}^{0}$ is insoluble and undergoes long-range transport, becoming part of the global atmospheric mercury burden. $\mathrm{Hg}^{2+}$, on the other hand, is soluble and is generally thought to be deposited locally and/or regionally. Also, $\mathrm{Hg}^{2+}$ can be methylated in lakes and streams (2).

The data show that for the Blount Station, the mercury at the stack is a mixture of both $\mathrm{Hg}^{0}$ and $\mathrm{Hg}^{2+}$. As can be seen from the tables, for all fuel conditions, the percentage of particulate-bound mercury is high and the ESP essentially removes all of the particulate-bound mercury. However, the 
Table 14. Mercury Speciation Results for Coal

\section{ESP Inlet}

ESP Outlet

Particulate-

Particulate-

Total $\mathrm{Hg}$, Bound $\mathrm{Hg}, \quad \mathrm{Hg}^{0}, \quad \mathrm{Hg}^{2+}$, Total $\mathbf{H g}$, Bound $\mathbf{H g}, \quad \mathbf{H g}^{0}, \quad \mathbf{H g}^{2+}$, \begin{tabular}{llllllll}
$\mu \mathrm{g} / \mathbf{N m}^{3}$ & $\boldsymbol{\mu g} / \mathrm{Nm}^{3}$ & $\mu \mathrm{g} / \mathbf{N m}^{3}$ & $\boldsymbol{\mu g} / \mathbf{N m}^{3}$ & $\boldsymbol{\mu g} / \mathrm{Nm}^{3}$ & $\boldsymbol{\mu g} / \mathbf{N m}^{3}$ & $\mu \mathrm{g} / \mathrm{Nm}^{3}$ & $\boldsymbol{\mu g} / \mathbf{N m}^{3}$ \\
\hline
\end{tabular}

\begin{tabular}{lllll|rrrr}
\hline & 4.92 & 2.13 & 0.29 & 2.50 & 3.68 & $<0.002$ & 1.37 & 2.31 \\
& 5.19 & 3.49 & 0.21 & 1.48 & 3.40 & 0.020 & 1.28 & 2.10 \\
& 5.37 & 3.99 & 0.17 & 1.21 & 2.52 & $<0.002$ & 0.99 & 1.54 \\
\hline Average & 5.16 & 3.20 & 0.22 & 1.73 & 3.20 & 0.007 & 1.21 & 1.98 \\
Std. Dev. & 0.23 & 0.96 & 0.06 & 0.68 & 0.60 & 0.011 & 0.20 & 0.40 \\
\hline
\end{tabular}

Table 15. Mercury Speciation Results for Coal plus Paper

ESP Inlet

ESP Outlet

Particulate-

Particulate-

Total $\mathbf{H g}$, Bound $\mathbf{H g}, \quad \mathbf{H g}^{0}, \quad \mathbf{H g}^{2+}, \quad$ Total $\mathbf{H g}$, Bound $\mathbf{H g}, \quad \mathbf{H g}^{\mathbf{0}}, \quad \mathbf{H g}^{2+}$, $\mu \mathrm{g} / \mathrm{Nm}^{3} \quad \mu \mathrm{g} / \mathrm{Nm}^{3} \quad \mu \mathrm{g} / \mathrm{Nm}^{3} \quad \mu \mathrm{g} / \mathrm{Nm}^{3} \quad \mu \mathrm{g} / \mathrm{Nm}^{3} \quad \mu \mathrm{g} / \mathrm{Nm}^{3} \quad \mu \mathrm{g} / \mathrm{Nm}^{3} \quad \mu \mathrm{g} / \mathrm{Nm}^{3}$

\begin{tabular}{lcccc|cccc} 
& $\boldsymbol{\mu g} / \mathbf{N m}^{\mathbf{3}}$ & $\boldsymbol{\mu g} / \mathbf{N m}^{\mathbf{3}}$ & $\boldsymbol{\mu g} / \mathbf{N m}^{3}$ & $\boldsymbol{\mu g} / \mathbf{N m}^{3}$ & $\boldsymbol{\mu g} / \mathbf{N m}^{3}$ & $\boldsymbol{\mu g} / \mathbf{N m}^{3}$ & $\boldsymbol{\mu g} / \mathbf{N m}^{3}$ & $\boldsymbol{\mu g} / \mathbf{N m}^{3}$ \\
\hline & & & & & & & & \\
& 2.79 & 2.33 & 0.26 & 0.20 & 1.40 & 0.003 & 0.82 & 0.57 \\
& 2.09 & 1.92 & 0.15 & 0.03 & 1.39 & 0.005 & 0.84 & 0.55 \\
& 2.45 & 2.10 & 0.22 & 0.13 & 1.39 & 0.006 & 0.69 & 0.69 \\
& 3.72 & 3.30 & 0.20 & 0.22 & 1.91 & 0.004 & 0.90 & 1.01 \\
\hline Average & 2.76 & 2.41 & 0.21 & 0.15 & 1.52 & 0.004 & 0.81 & 0.71 \\
Std. Dev. & 0.70 & 0.62 & 0.05 & 0.09 & 0.26 & 0.001 & 0.09 & 0.21 \\
\hline
\end{tabular}

Table 16. Mercury Speciation Results for Coal plus Plastic

\section{ESP Inlet}

Particulate-

Total Bound $\mathbf{H g}, \quad \mathbf{H g}^{0}, \quad \mathbf{H g}^{2+}$,

$\mathrm{Hg}, \quad \mu \mathrm{g} / \mathrm{Nm}^{3} \quad \mu \mathrm{g} / \mathrm{Nm}^{3} \quad \mu \mathrm{g} / \mathrm{Nm}^{3}$ $\mu \mathrm{g} / \mathrm{Nm}^{3}$

\begin{tabular}{lcccc|rrrr}
\multicolumn{1}{c}{$\boldsymbol{\mu} \mathbf{g} / \mathbf{N m}$} & & & & & & & \\
& 3.61 & 2.25 & 0.39 & 0.97 & 2.21 & $<0.002$ & 0.92 & 1.29 \\
& 2.81 & 2.42 & 0.27 & 0.12 & 1.42 & 0.013 & 0.70 & 0.70 \\
& 3.27 & 2.08 & 0.36 & 0.83 & 2.24 & 0.008 & 0.87 & 1.36 \\
& 3.20 & 1.42 & 0.49 & 1.29 & 2.65 & $<0.002$ & 1.04 & 1.60 \\
\hline Average & 3.22 & 2.04 & 0.38 & 0.80 & 2.13 & 0.006 & 0.88 & 1.24 \\
Std. Dev. & 0.33 & 0.44 & 0.09 & 0.49 & 0.51 & 0.006 & 0.14 & 0.38 \\
\hline
\end{tabular}


Table 17. Mercury Speciation Results for Coal, Paper, and Plastic Blend

\section{$\underline{\text { ESP Inlet }}$}

ESP Outlet

\begin{tabular}{|c|c|c|c|c|c|c|c|c|}
\hline & $\begin{array}{c}\text { Total } \\
\text { Hg, } \\
\mu \mathrm{g} / \mathrm{Nm}^{3}\end{array}$ & $\begin{array}{c}\text { Particulate- } \\
\text { Bound } \mathrm{Hg} \text {, } \\
\boldsymbol{\mu g} / \mathrm{Nm}^{3}\end{array}$ & $\begin{array}{c}\mathbf{H g}^{0}, \\
\mu \mathrm{g} / \mathbf{N m}^{3}\end{array}$ & $\begin{array}{c}\mathrm{Hg}^{2+}, \\
\mu \mathrm{g} / \mathrm{Nm}^{3}\end{array}$ & $\begin{array}{c}\text { Total Hg, } \\
\mu \mathrm{g} / \mathrm{Nm}^{3}\end{array}$ & $\begin{array}{c}\text { Particulate- } \\
\text { Bound Hg, } \\
\mu_{\mathrm{\mu g} / \mathrm{Nm}^{3}}\end{array}$ & $\begin{array}{c}\mathrm{Hg}^{0}, \\
\mu \mathrm{g} / \mathrm{Nm}^{3}\end{array}$ & $\begin{array}{c}\mathrm{Hg}^{2+} \\
\mu \mathrm{g} / \mathrm{Nm}^{3}\end{array}$ \\
\hline & 2.70 & 2.25 & 0.24 & 0.21 & 1.62 & 0.047 & 0.84 & 0.74 \\
\hline & 3.07 & 2.30 & 0.28 & 0.49 & 1.84 & - & 1.00 & 0.84 \\
\hline & $-^{\mathrm{a}}$ & - & - & - & 0.91 & 0.016 & 0.47 & 0.42 \\
\hline & 3.16 & 2.81 & 0.24 & 0.11 & 1.44 & 0.028 & 0.85 & 0.56 \\
\hline Average & 2.98 & 2.45 & 0.25 & 0.27 & 1.45 & 0.030 & 0.79 & 0.64 \\
\hline Std. Dev. & 0.24 & 0.31 & 0.02 & 0.20 & 0.40 & 0.016 & 0.23 & 0.19 \\
\hline
\end{tabular}

${ }^{a}$ Sample was invalid because filter was broken.

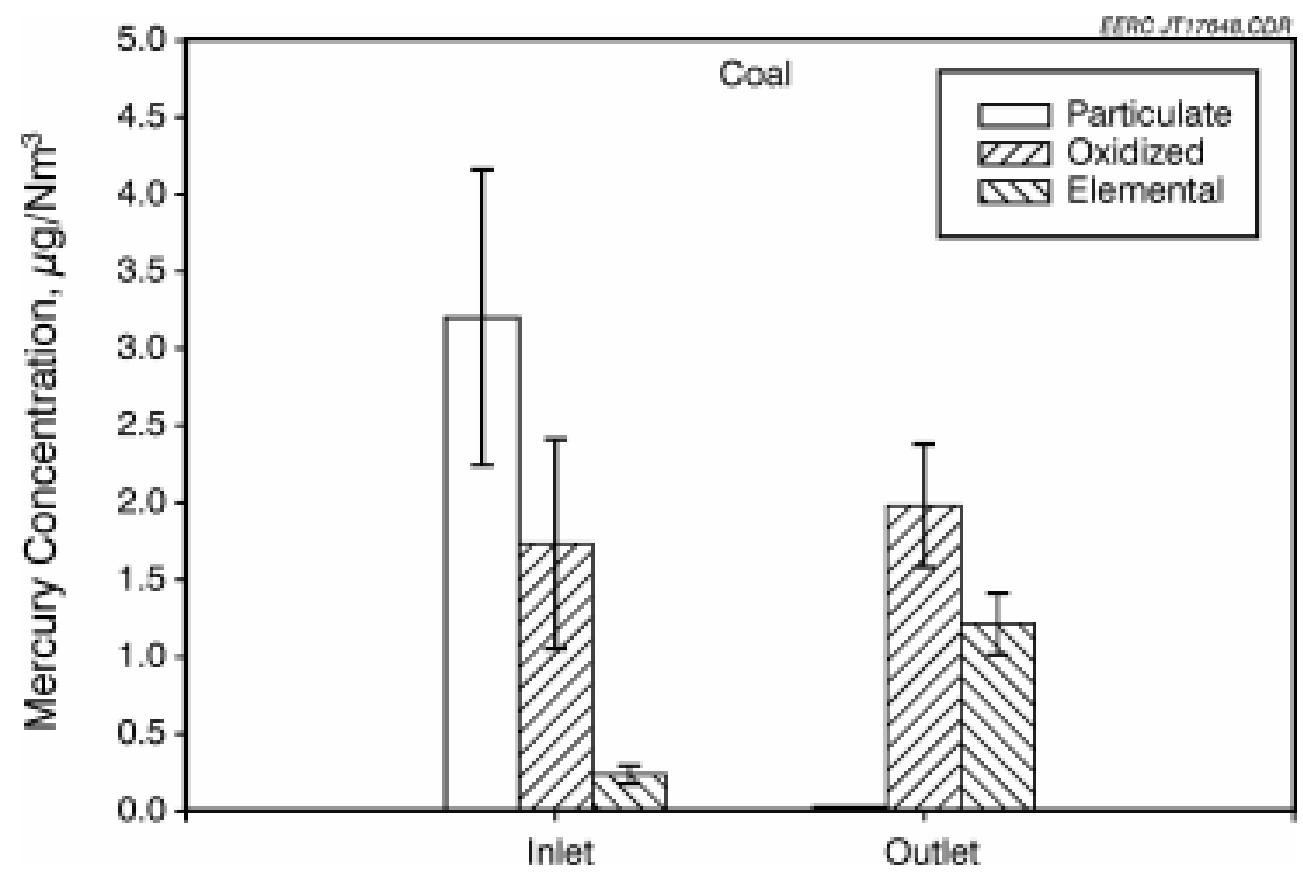

Figure 5. Mercury removal across the ESP with coal only. 


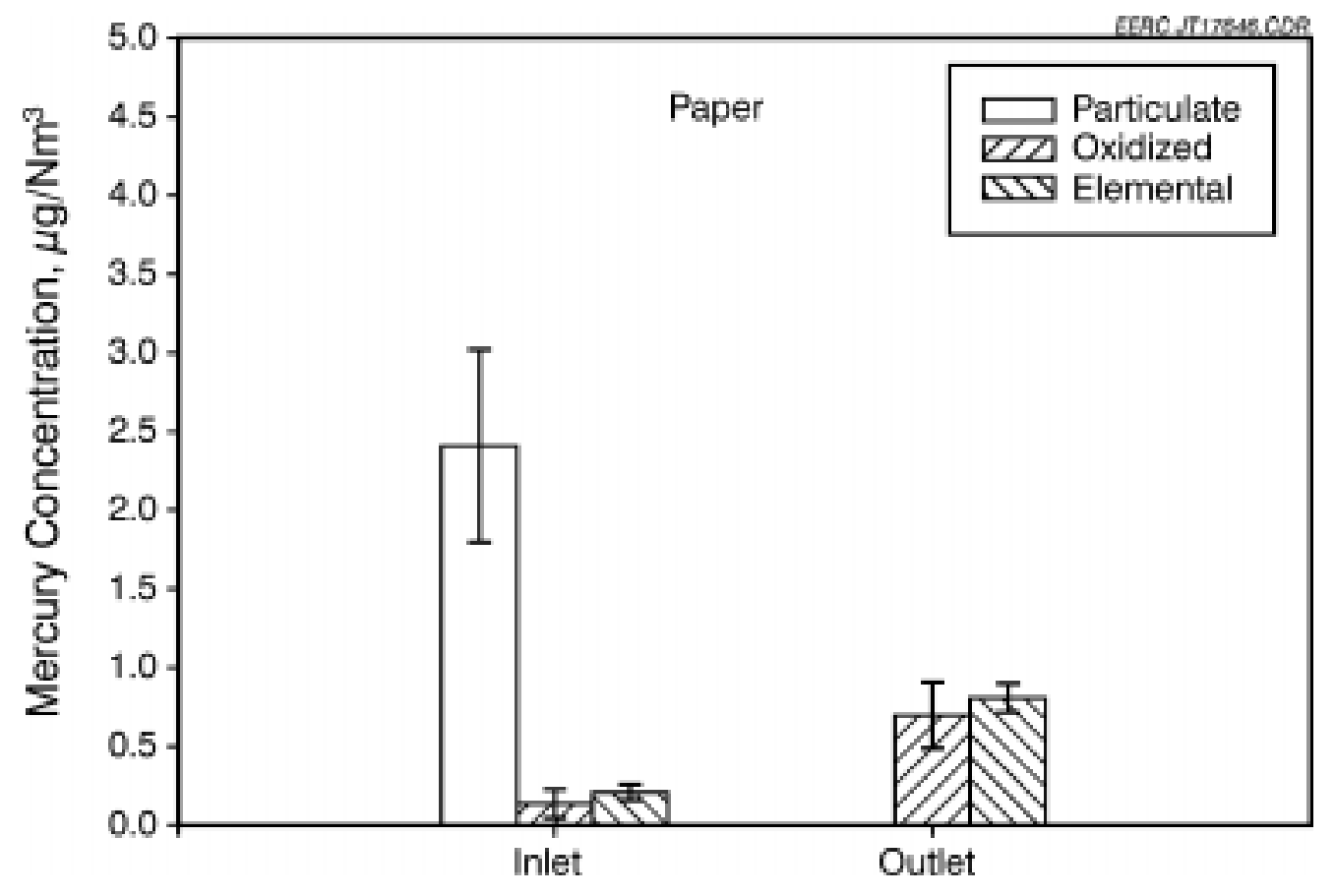

Figure 6. Mercury removal across the ESP with coal and paper.

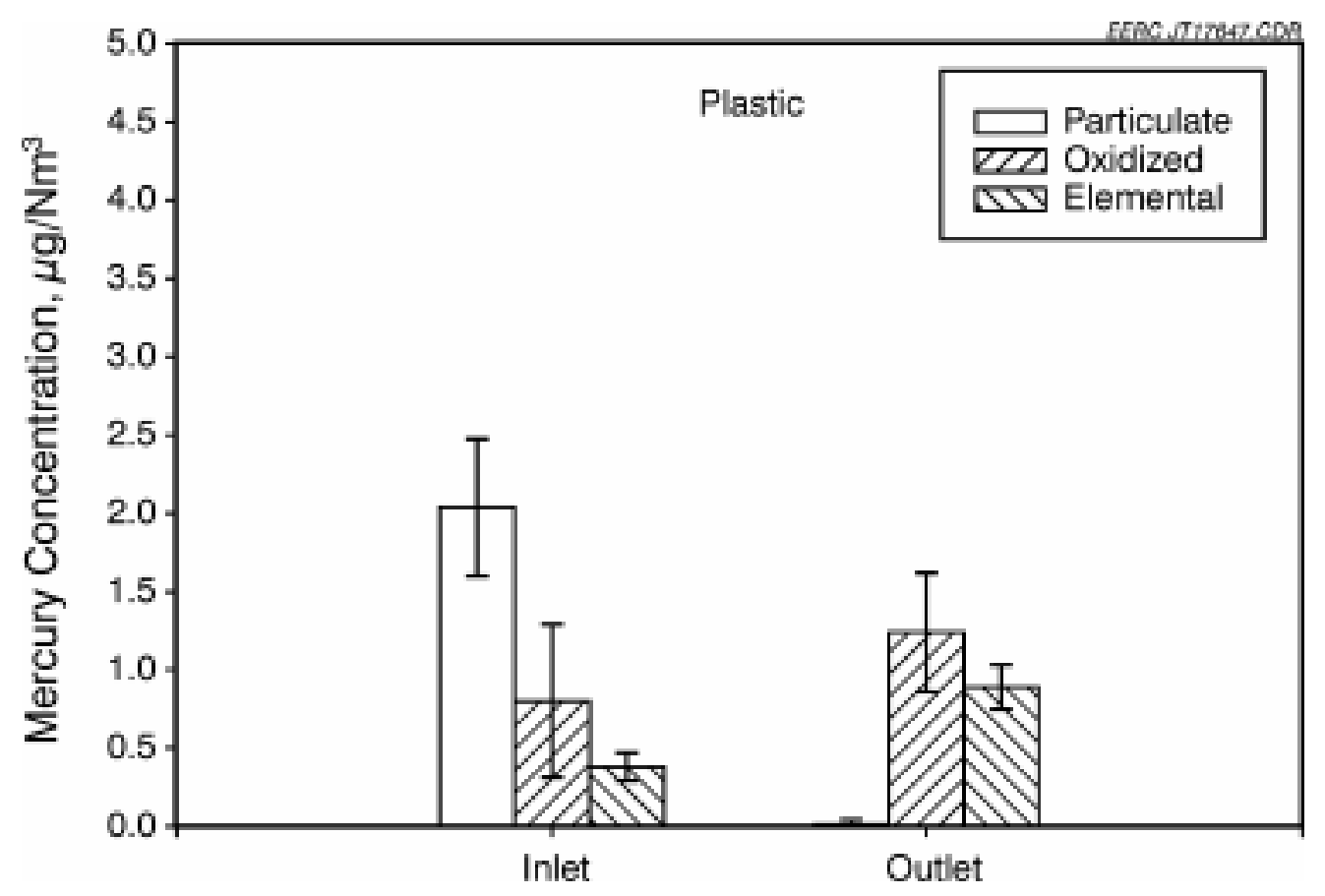

Figure 7. Mercury removal across the ESP with coal and plastic. 


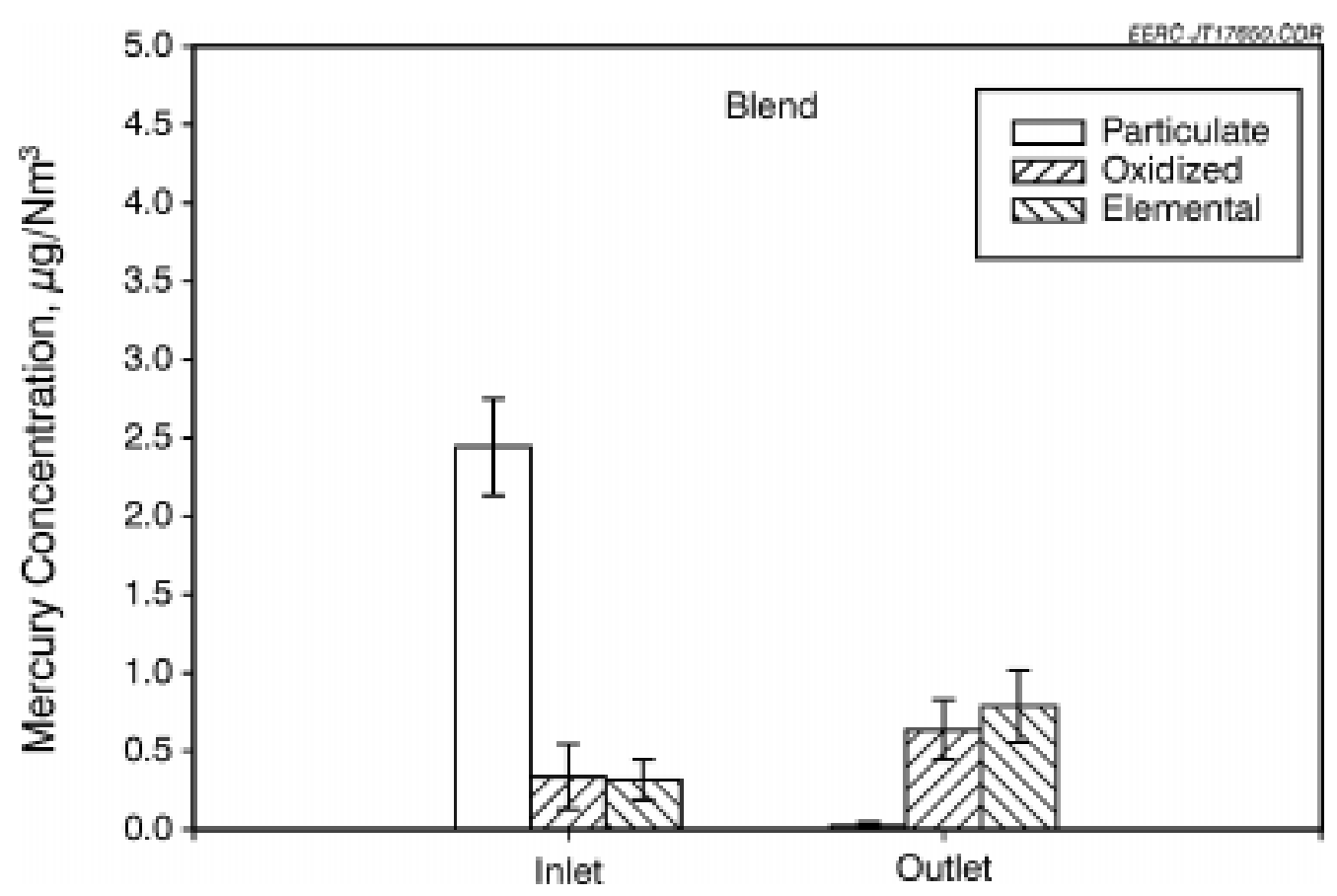

Figure 8. Mercury removal across the ESP with coal, paper, and plastic.

concentration of vapor-phase mercury is greater at the outlet of the ESP than at the inlet, as is shown in Table 18. Two possibilities can explain the data. The first, and most likely reason, is that additional mercury was captured by the ash collected on the filter of the $\mathrm{OH}$ sampling method at the inlet of the ESP. This occurs when the fly ash has a strong affinity to adsorb mercury as it does at the Blount Station (4). The second possibility is that captured mercury is being offgassed from the ESP. Although it is possible for this to occur because of the presence of $\mathrm{NO}_{\mathrm{x}}$ and $\mathrm{SO}_{2}$ in the flue gas, it is not very likely (6).

For all cases, the PDF decreases the concentration of mercury in the flue gas compared to burning the coal only. Moreover, each of the vapor-phase species is also reduced compared to burning the coal only. Table 19 summarizes the vapor-phase mercury concentrations for each of the four boiler conditions and shows the reduction of mercury species compared to the coal, as well

Table 18. Concentration of Vapor-Phase Mercury Across the ESP

\begin{tabular}{lcc}
\hline Fuel & $\begin{array}{c}\text { ESP Inlet } \\
\text { Vapor-Phase Hg, } \\
\boldsymbol{\mu g}^{-\mathbf{N m}^{3}}\end{array}$ & $\begin{array}{c}\text { ESP Outlet } \\
\text { Vapor-Phase Hg, } \\
\boldsymbol{\mu g}_{\mathbf{N}} \mathbf{N m}^{\mathbf{3}}\end{array}$ \\
\hline Coal & 1.95 & 3.19 \\
Coal and Paper & 0.36 & 1.52 \\
Coal and Plastic & 1.18 & 2.12 \\
Coal, Paper, Plastic Blend & 0.52 & 1.43 \\
\hline
\end{tabular}


Table 19. Effect of PDF on Outlet Vapor-Phase Mercury Species

\begin{tabular}{lcc|cc|c}
\hline & \multicolumn{2}{c|}{$\mu \mathbf{g} / \mathbf{N m}^{\mathbf{3}}$} & \multicolumn{2}{c|}{ \% Reduction } & \\
& $\mathbf{H g}^{\mathbf{0}}$ & $\mathbf{H g}^{\mathbf{2 +}}$ & $\mathbf{H g}^{\mathbf{0}}$ & $\mathbf{H g}^{\mathbf{2 +}}$ & \% $\mathbf{P D F}^{\mathbf{b}}$ \\
\cline { 2 - 6 } Coal & 1.21 & 1.98 & - & - & 0 \\
Coal and Paper & 0.81 & 0.71 & 33 & 64 & 16 \\
Coal and Plastic & 0.88 & 1.24 & 27 & 37 & 22 \\
Coal, Paper, Plastic Blend & 0.79 & 0.64 & 35 & 68 & 22 \\
\hline
\end{tabular}

${ }^{a}$ Compared to coal.

${ }^{b}$ By heat input.

as the average percent of PDF during the runs. Figure 9 shows the speciated mercury at the stack for the four operating conditions. The data show that when the plastic is added, the decrease is due primarily to dilution of mercury in the fuel, since the plastic has essentially no mercury. There does appear to be a real decrease in mercury emitted when paper is added to the fuel mix. The change in concentration of $\mathrm{Hg}^{0}$ appears to be essentially due to dilution, but the concentration of $\mathrm{Hg}^{2+}$ decreases significantly compared to the coal. The most likely explanation for this is that the addition of the paper changes the chemistry favorably such that a higher percentage of the $\mathrm{Hg}^{2+}$ is removed prior to the stack which reduces the mercury emissions.

\subsection{Mercury CEM Results}

A Semtech Hg 2010 and the Tekran CEMs were used to measure total mercury at the ESP outlet. Although the Semtech was developed to measure $\mathrm{Hg}^{0}$, using a conversion system designed

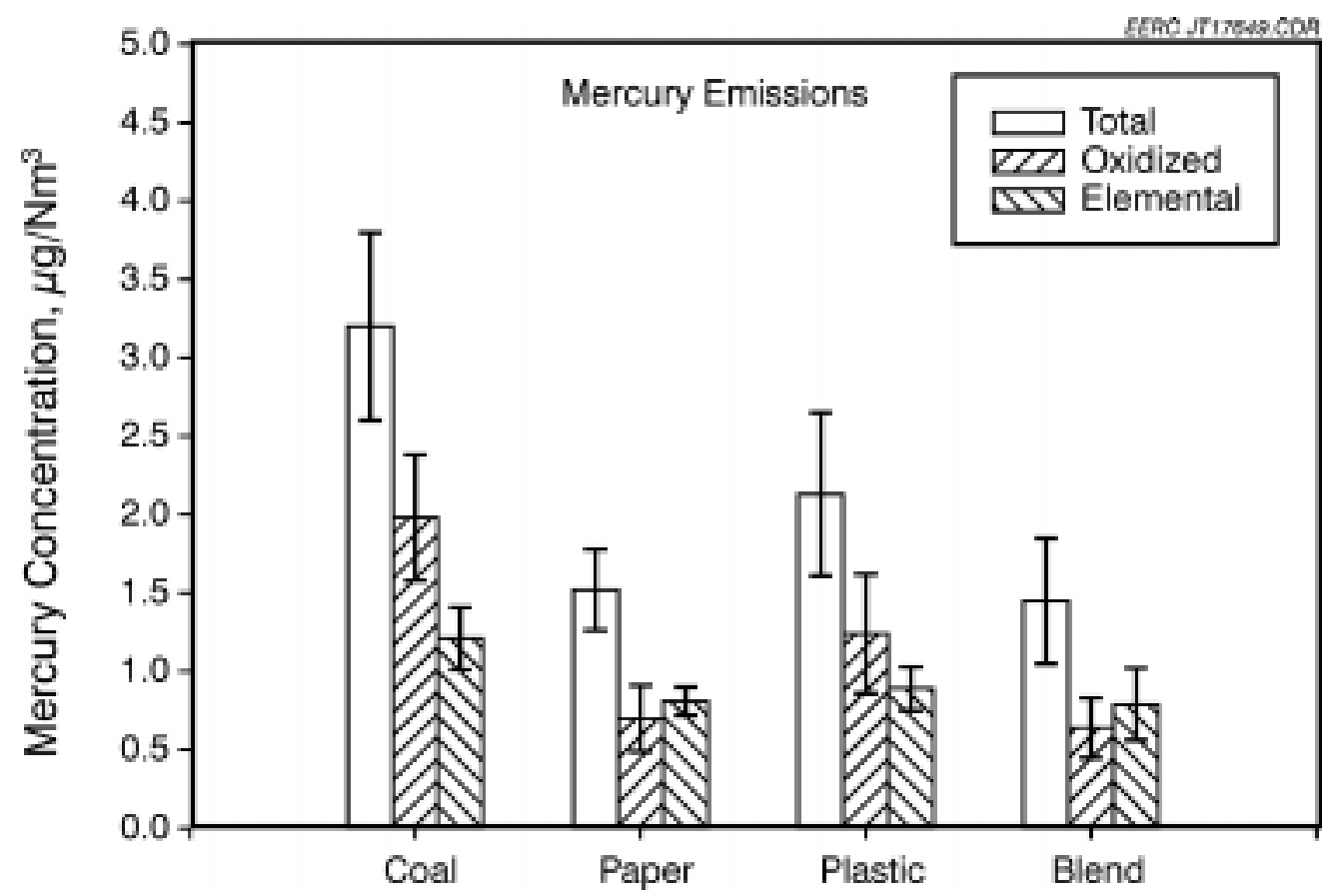

Figure 9. Speciated mercury emissions at the stack. 
at the EERC, the instrument was able to measure total mercury. For this project, it was originally intended that the instruments would provide mercury speciation data. However, it was only on the last 2 days that the conversion system was operating in speciation mode. A comparison between the $\mathrm{CEM}$ data and the $\mathrm{OH}$ method data is shown in Figures 10-17. As can be seen from the graphs, the CEM results compare quite well with the results obtained using the $\mathrm{OH}$ method.

\subsection{Mercury Emission Factors}

The emission factors at the outlet of the ESP for each of the fuel mixes are shown in Table 20. The emission factors were calculated using $F_{d}$ values according to EPA Method 19. The emission factors for total mercury averaged from a high of $2.37 \mathrm{lb} / 10^{12}$ Btu when burning only coal to a low of $1.04 \mathrm{lb} / 10^{12}$ Btu when burning a blend of coal, paper, and plastic. Based on the results reported in the Comprehensive Assessment of Toxic Emissions from Coal-Fired Power Plants (7), these emission factors are on the very low end for coal-fired boilers. The results from that report showed that the emission factors for mercury ranged from 2 to $22 \mathrm{lb} / 10^{12} \mathrm{Btu}$.

Using the emission factors calculated at both the inlet and outlet of the ESP, the mercury removal across the ESP was calculated for each test. These results are shown in Table 21. Although it is clear there is a substantial reduction in mercury emissions when PDFs are burned compared to coal, the average removal across the ESP seems to be independent of fuel. The average removal was about $40 \%$.

\subsection{Mercury Balances}

Two mercury balances were calculated for the Blount Station. The first was the overall unit balance, and the second was across the ESP. Each mercury balance was determined by comparing

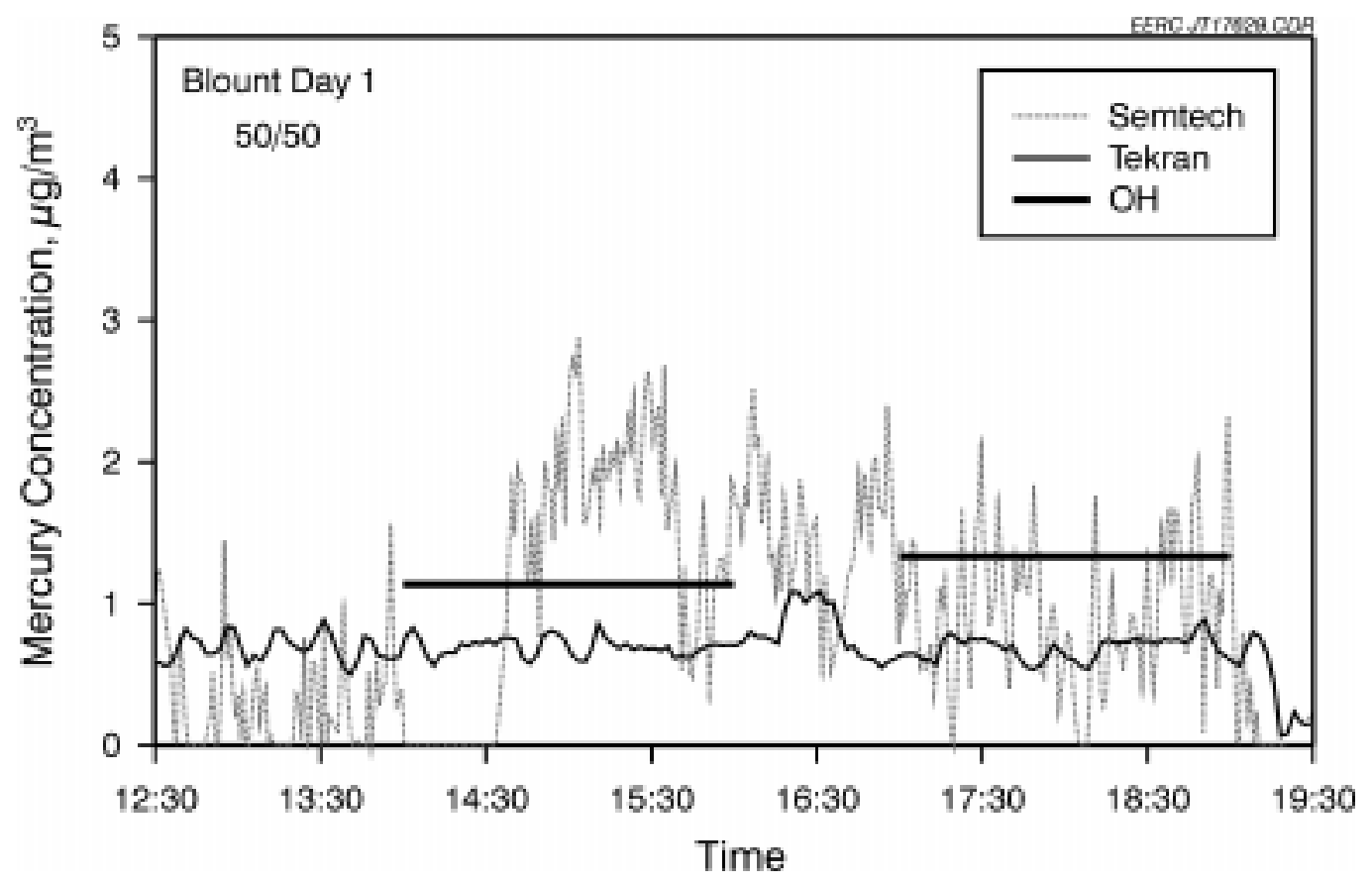

Figure 10. CEM for Test Day 1. 




Figure 11. CEM for Test Day 2.

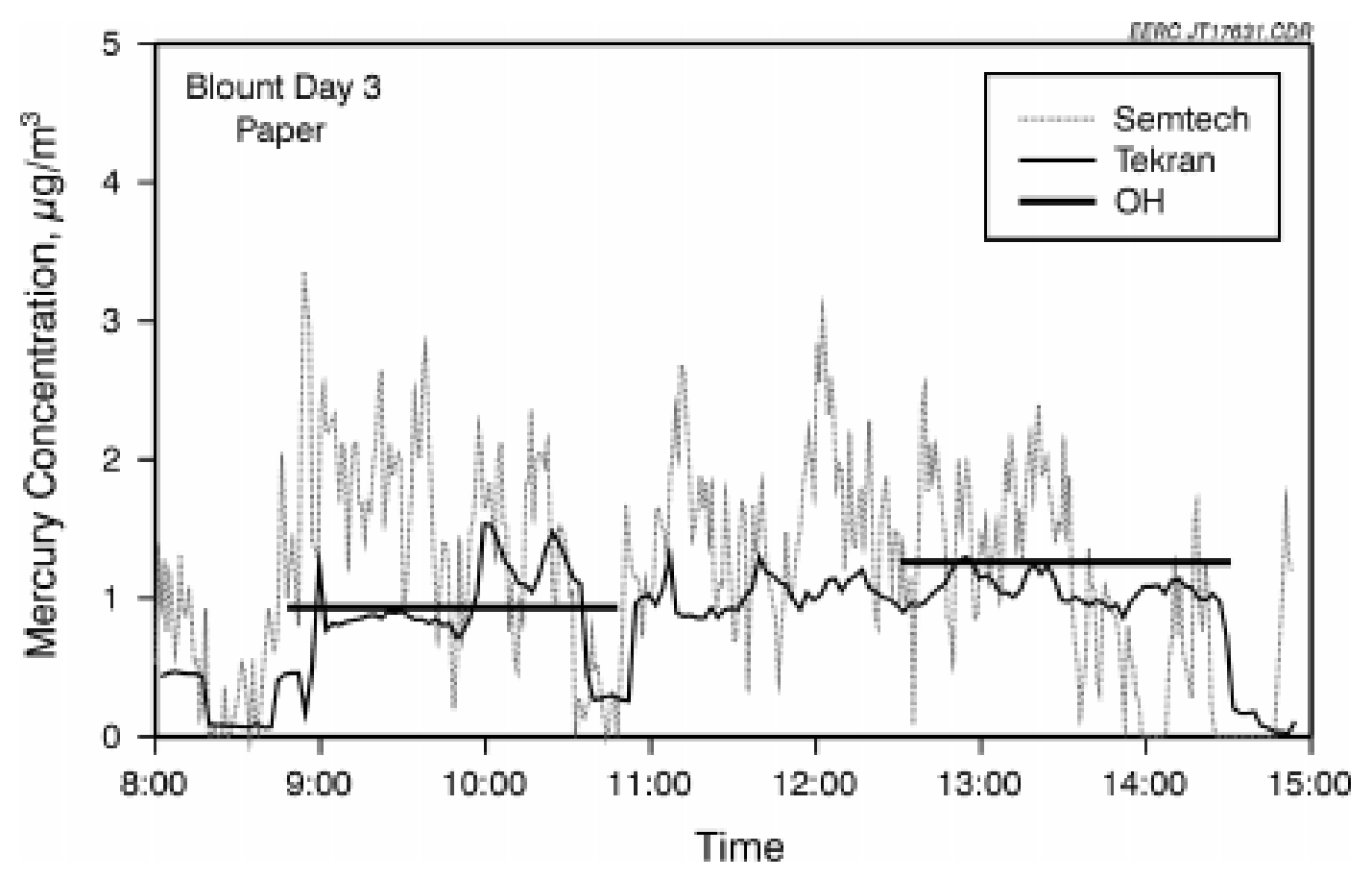

Figure 12. CEM for Test Day 3. 




Figure 13. CEM for Test Day 4.

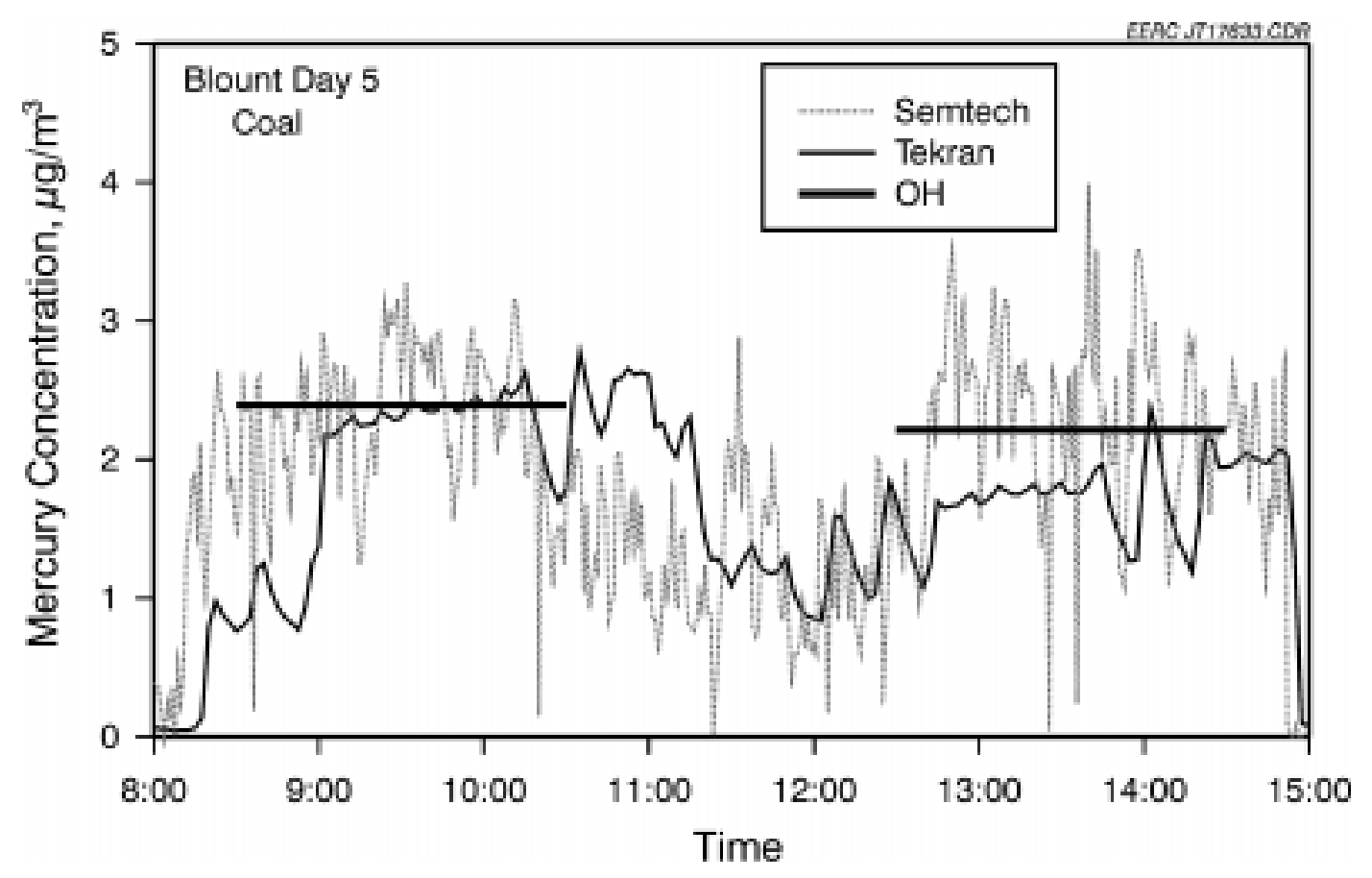

Figure 14. CEM for Test Day 5. 


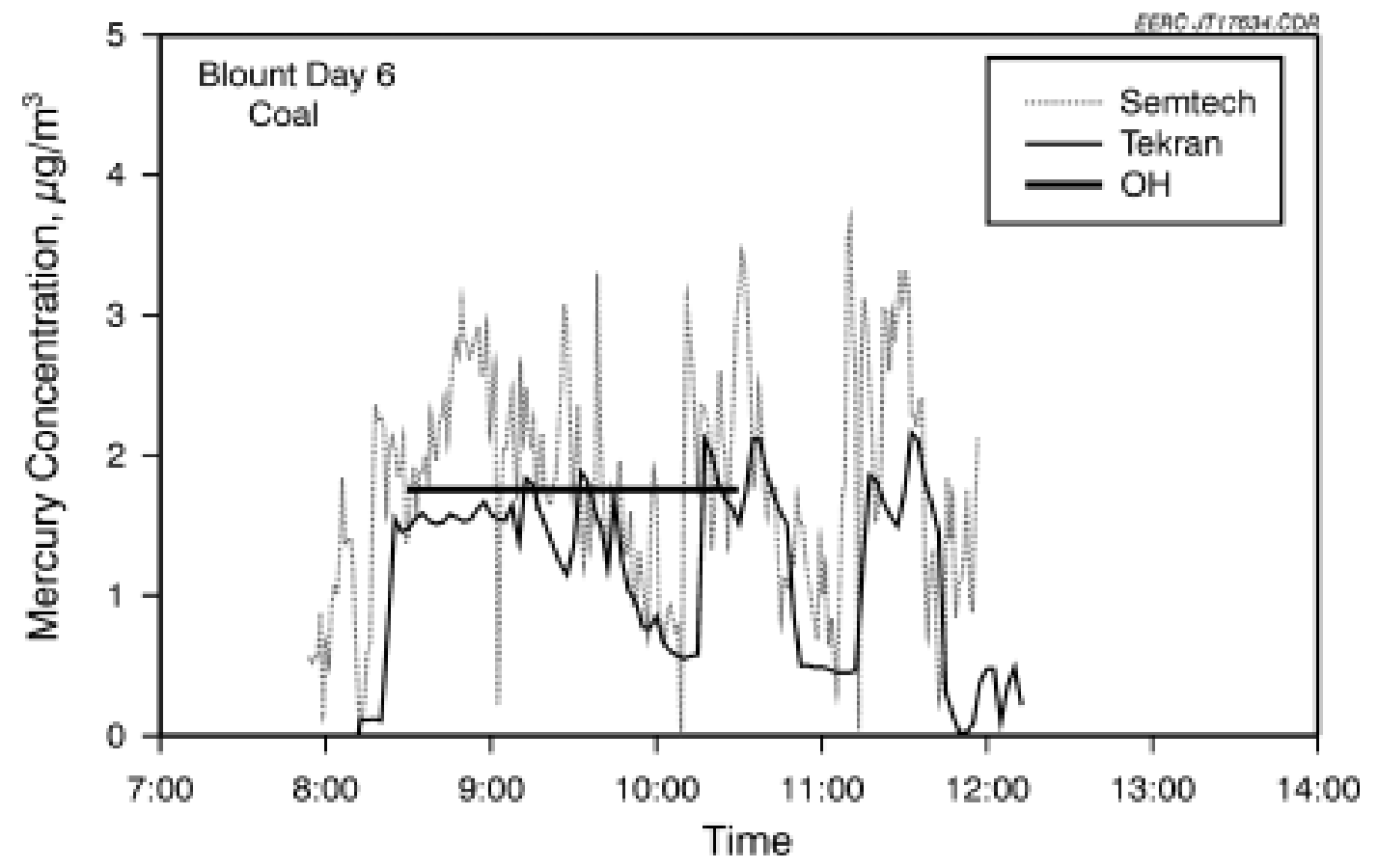

Figure 15. CEM for Test Day 6.



Figure 16. CEM for Test Day 7. 




Figure 17. CEM for Test Day 8.

Table 20. Emission Factors for Mercury at the Outlet of the ESP Firing Coal

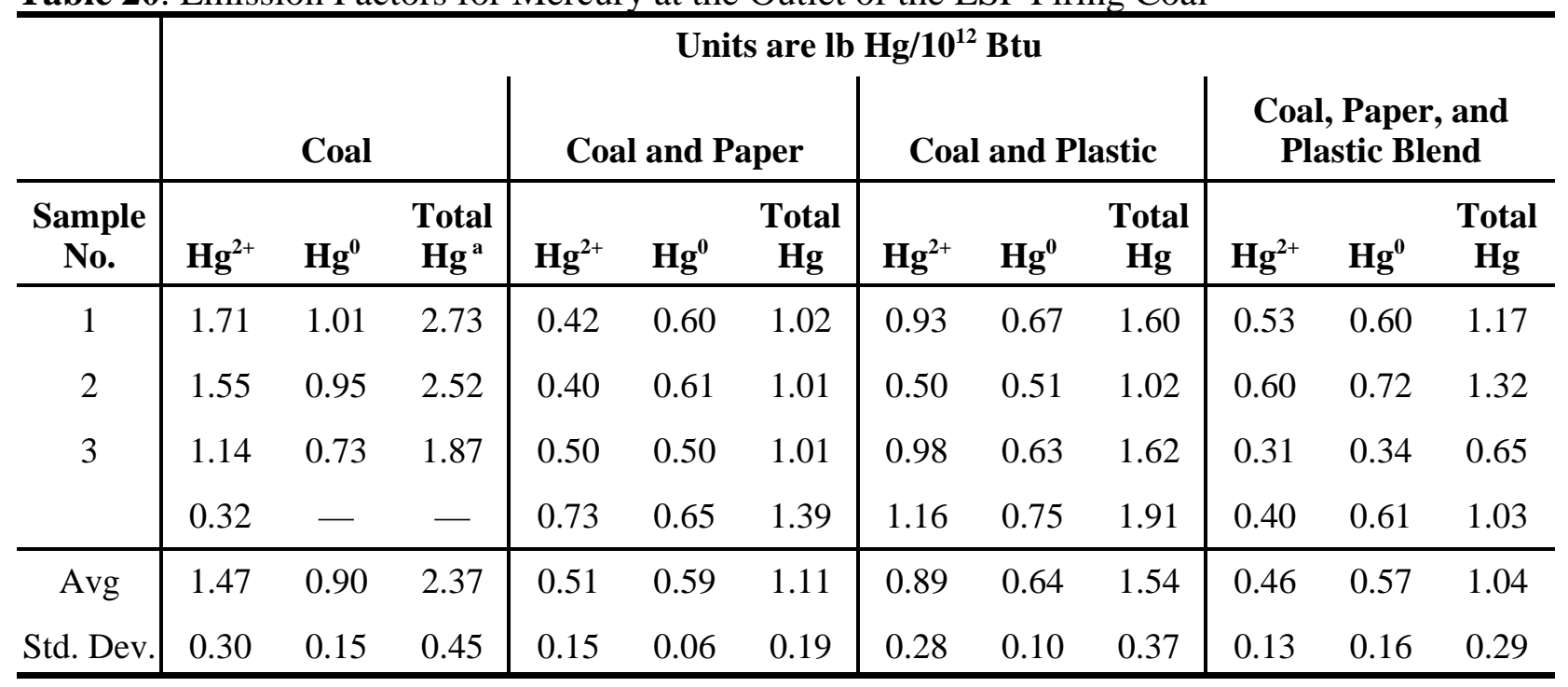

${ }^{a}$ All total mercury values include any particulate-bound mercury. The values in all cases are less than $0.04 \mathrm{lb} \mathrm{Hg} / 10^{12} \mathrm{Btu}$. 
Table 21. Mercury Speciation

\begin{tabular}{|c|c|c|c|c|c|c|c|c|c|c|}
\hline Sample & Fuel & $\begin{array}{c}\text { Inle } \\
\text { Total } \\
\text { Hg } \\
\end{array}$ & $\mathbf{H g}_{\mathrm{p}}$ & $\mathrm{Hg}^{2+}$ & $\mathbf{H g}^{0}$ & $\begin{array}{r}\text { Sta } \\
\text { Total } \\
\text { Hg } \\
\end{array}$ & k Mercu & $\mathbf{H g}^{2+}$ & $\mathbf{H g}^{\mathbf{0}}$ & $\begin{array}{c}\text { Removal, } \\
\%\end{array}$ \\
\hline D1-1 & Blend & 1.94 & 1.62 & 0.15 & 0.17 & 1.17 & 0.034 & 0.53 & 0.60 & 40 \\
\hline D1-2 & Blend & 2.21 & 1.65 & 0.36 & 0.20 & 1.32 & NA & 0.60 & 0.72 & 40 \\
\hline D4-2 & Blend & 2.27 & 2.02 & 0.08 & 0.17 & 1.03 & 0.020 & 0.40 & 0.61 & 55 \\
\hline D5-1 & Coal & 3.65 & 1.58 & 1.86 & 0.22 & 2.73 & $<0.002$ & 1.71 & 1.01 & 25 \\
\hline D5-2 & Coal & 3.85 & 2.59 & 1.10 & 0.16 & 2.52 & 0.015 & 1.55 & 0.95 & 34 \\
\hline D6-1 & Coal & 3.98 & 2.96 & 0.90 & 0.13 & 1.87 & $<0.002$ & 1.14 & 0.73 & 53 \\
\hline D2-1 & Coal and paper & 2.03 & 1.70 & 0.14 & 0.19 & 1.02 & 0.002 & 0.42 & 0.60 & 50 \\
\hline D2-2 & Coal and paper & 1.52 & 1.39 & 0.02 & 0.11 & 1.01 & 0.004 & 0.40 & 0.61 & 34 \\
\hline D3-1 & Coal and paper & 1.77 & 1.52 & 0.09 & 0.16 & 1.01 & 0.005 & 0.50 & 0.50 & 43 \\
\hline D3-2 & Coal and paper & 2.70 & 2.40 & 0.16 & 0.14 & 1.39 & 0.003 & 0.73 & 0.65 & 49 \\
\hline D7-1 & Coal and plastic & 2.61 & 1.63 & 0.70 & 0.28 & 1.60 & $<0.002$ & 0.93 & 0.67 & 39 \\
\hline D7-2 & Coal and plastic & 2.03 & 1.75 & 0.09 & 0.19 & 1.02 & 0.009 & 0.50 & 0.51 & 50 \\
\hline D8-1 & Coal and plastic & 2.36 & 1.50 & 0.60 & 0.26 & 1.62 & 0.006 & 0.98 & 0.63 & 31 \\
\hline D8-2 & Coal and plastic & 2.31 & 1.03 & 0.93 & 0.35 & 1.91 & $<0.002$ & 1.16 & 0.75 & 17 \\
\hline
\end{tabular}

the rate of mercury entering to the rate of mercury leaving. To compute the overall mercury balances, the only source of mercury used was the mercury in the fuel. The only other possible source of mercury entering Unit 9 was the combustion air. However, the concentration of mercury in the combustion air is extremely low compared to the flue gas and is, therefore, insignificant. Sources of mercury exiting Unit 9 were the cyclone ash, the ESP ash, and the flue gas that went to the stack.

The mercury flow rates were calculated for each run, in lb/hr, at each location. The ESP inlet and outlet dust loading (shown in Table 3) were used along with the flue gas flow rate to calculate the mercury balance across the ESP; the rate of mercury entering the ESP was compared to the rate of mercury leaving the ESP.

The results of these calculations are included in Table 22. The results of the mass balance calculations show excellent closure for the mercury testing (average 98\% from inlet to the stack). However, for several of the tests, the mercury balance was somewhat high, $>150 \%$. As stated earlier, these calculations require accurate flow rates for the fuel and the flue gas. These measurements are difficult to make accurately and are generally not given a high priority by power stations when specifying equipment.

\subsection{Flue Gas Chloride Results}

Because it is thought the level of chlorides in the flue gas stream may influence mercury speciation, an EPA Method 26A sample train was completed for each day of sampling (except for the first day). This sampling method was designed to measure both the $\mathrm{HCl}$ concentration in the gas stream and the $\mathrm{Cl}_{2}$. In practice, the method does not work very well as a chloride speciation 
Table 22. Mercury Flow Rates and Balances

\begin{tabular}{|c|c|c|c|c|c|c|c|c|}
\hline \multirow[b]{2}{*}{$\begin{array}{l}\text { Run } \\
\text { No. }\end{array}$} & \multicolumn{5}{|c|}{ Mercury Flow Rate $\left(\mathrm{lb} / \mathrm{hr} \times \mathbf{1 0}^{-3}\right)$} & \multicolumn{3}{|c|}{ Mercury Balance (\%) } \\
\hline & $\begin{array}{c}\text { Fuel }^{\text {a }} \\
\text { Hg }\end{array}$ & $\begin{array}{c}\text { Dust Bin } \\
\text { Hopper } \\
\text { Ash } \\
\end{array}$ & $\begin{array}{c}\text { Flue Gas } \\
\text { ESP Inlet }\end{array}$ & $\begin{array}{c}\text { ESP Hopper } \\
\text { Ash } \\
\end{array}$ & $\begin{array}{c}\text { Flue Gas at } \\
\text { the Stack }\end{array}$ & $\begin{array}{c}\text { Combustor } \\
\text { (inlet/fuel) }\end{array}$ & $\begin{array}{c}\text { ESP } \\
\text { (outlet/inlet) }\end{array}$ & $\begin{array}{c}\text { Unit } \\
\text { (outlet/fuel) } \\
\end{array}$ \\
\hline D1-1 & 1.10 & 0.16 & 1.37 & 0.74 & 0.65 & 124 & 101 & 140 \\
\hline D1-2 & 1.10 & 0.17 & 1.57 & 0.54 & 0.75 & 143 & 82 & 133 \\
\hline D2-1 & 1.14 & 0.20 & 1.33 & 0.80 & 0.53 & 117 & 100 & 134 \\
\hline D2-2 & 1.15 & 0.20 & 0.98 & 0.56 & 0.49 & 85 & 107 & 108 \\
\hline D3-1 & 1.09 & 0.23 & 1.08 & 0.67 & 0.47 & 99 & 106 & 126 \\
\hline D3-2 & 1.17 & 0.19 & 1.61 & 1.46 & 0.65 & 138 & 131 & 197 \\
\hline D4-2 & 0.95 & 0.22 & 1.39 & 0.48 & 0.51 & 146 & 72 & 127 \\
\hline D5-1 & 1.36 & 0.19 & 2.08 & 0.78 & 1.25 & 153 & 97 & 163 \\
\hline D5-2 & 1.36 & 0.23 & 2.26 & 0.81 & 1.18 & 166 & 88 & 162 \\
\hline D6-1 & 1.36 & 0.26 & 2.28 & 0.89 & 0.88 & 168 & 77 & 149 \\
\hline D7-1 & 1.10 & 0.21 & 1.58 & 0.74 & 0.77 & 143 & 95 & 155 \\
\hline D7-2 & 1.03 & 0.22 & 1.32 & 0.68 & 0.49 & 126 & 90 & 135 \\
\hline D8-1 & 1.09 & 0.20 & 1.43 & 0.67 & 0.77 & 131 & 101 & 151 \\
\hline D8-2 & 1.08 & 0.13 & 1.42 & 0.87 & 0.91 & 132 & 125 & 177 \\
\hline
\end{tabular}

a PDF contains no $\mathrm{Hg}$; therefore, all of the mercury in the fuel comes from the coal.

measurement method, but does provide a good measurement of the total chloride concentration in the flue gas. The EPA Method 26A results are shown in Table 23. It is clear the addition of plastic increases the overall chloride concentration in the gas. However, the additional chloride due to adding plastic (and to a lesser degree paper) did not appear to have any effect on the overall mercury speciation results.

\subsection{QUALITY ASSURANCE/QUALITY CONTROL}

An overall QA/QC program in place at the EERC is designed to maintain overall data integrity. However, additional procedures were instituted specifically for this project.

\subsection{Instrument Setup and Calibration}

The instrument used in the field for mercury determination was a Leeman Labs PS200 CVAAS. To measure mercury, the instrument was set up for absorption at $253.7 \mathrm{~nm}$ with a carrier gas of nitrogen and $10 \% \mathrm{w} / \mathrm{v}$ stannous chloride in $10 \% \mathrm{v} / \mathrm{vCl}$ as the reductant. Each day, the drying tube and acetate trap were replaced and the tubing checked. The rinse container was cleaned and filled with fresh solution of $10 \% \mathrm{v} / \mathrm{v} \mathrm{HCl}$. After the pump and lamp were turned on and warmed up for $45 \mathrm{~min}$, the aperture was set to manufacturer specifications. A four-point calibration curve was then completed using matrix-matched standards. The detector response for a given standard was logged and compared to specifications to ensure the instrument had been 
Table 23. Chloride Concentrations in the Flue Gas

\begin{tabular}{lcc}
\hline Day & Fuel & $\begin{array}{c}\text { Chloride } \\
\text { Concentration, } \\
\text { ppmv }\end{array}$ \\
\hline 2 & Coal and paper & 17.9 \\
3 & Coal and paper & 20.9 \\
4 & Coal, paper, and plastic blend & 73.9 \\
5 & Coal & 17.2 \\
6 & Coal & 7.8 \\
7 & Coal and plastic & 51.5 \\
8 & Coal and plastic & 59.8 \\
\hline
\end{tabular}

properly set up. A QC standard of a known analyte concentration was analyzed immediately after the instrument was standardized in order to verify the calibration. This QC standard was prepared from a different stock than the calibration standards. The values obtained were required to read within $5 \%$ of the true value before the instrument was used. After the initial QC standardizationswere completed, standards were run every five samples to check the slope of the calibration curve. All samples were run in duplicate, and one in every ten samples was spiked to verify analyte recovery. A QC chart is maintained at the EERC to monitor the long-term precision of the instrument.

Prior to the testing, all gas-sampling equipment was calibrated according to the Quality Assurance Handbook for Air Pollution Measurement Systems: Volume III. Stationary Source Specific Methods. The uncertainty of the individual measurements was determined using the performance test codes in ANSI (American National Standards Institute)/ASME (American Society of Mechanical Engineers) PTC 19.1-1985, Part 1, Measurement Uncertainty, as a guideline.

\subsection{Presampling Preparation}

All data sheets, volumetric flasks, and petri dishes used for sample recovery were marked with preprinted labels. The liquid samples were recovered into premarked volumetric flasks and logged, then analyzed on-site. The filter samples were placed in premarked petri dishes and taken back to the EERC, where they were analyzed using mixed-acid digestion techniques. The labels contained identifying data, including date, time, run number, sample port location, and the name of the sampler.

\subsection{Glassware and Plasticware Cleaning and Storage}

All glass volumetric flasks and transfer pipets used in the preparation of analytical reagents and calibration standards were designated Class A to meet federal specifications. Prior to being used for the sampling, all glassware was washed with hot, soapy water, then rinsed with deionized water three times, soaked in $10 \% \mathrm{~V} / \mathrm{v}$ nitric acid for a minimum of $4 \mathrm{hr}$, rinsed an additional three times with deionized water, and dried. The glassware was then stored in closed containers until it was used at the plant. 


\subsection{Analytical Reagents}

All acids that were used for the analysis of mercury were trace-metal-grade. Other chemicals that were used in the preparation of analytical reagents were analytical-reagent-grade. The calibration standards used for instrument calibration and the QC standards used for calibration verification were purchased commercially and certified to be accurate within $\pm 0.5 \%$ and were traceable to NIST (National Institute of Standards and Technology) standard reference materials.

\subsection{Blanks}

As part of the QA/QC procedures for the testing at the Blount Station, both reagent blanks and field blanks were done. A field blank is defined as a complete impinger train including all glassware and solutions, that is taken out to the field during sampling and exposed to ambient conditions. These sample trains are then taken apart and the solutions recovered and analyzed in the same manner as those sample trains used for sampling activities. If the field blank shows contamination above instrument background, steps must be taken to eliminate or reduce the contamination to below background levels. However, in all cases, the field blanks and the reagent blanks taken during the sampling activities at the Blount Station were near or below detection limits, as is shown in Tables 24 and 25 .

All acids, chemical reagents, and deionized water used for mercury determination were analyzed for background levels of mercury. Each time a new batch of reagents was prepared, an aliquot was immediately taken and analyzed for mercury. Again, no mercury contamination was found.

\subsection{Spiked Samples}

In order to ensure that adequate levels of accuracy were maintained, spiked samples were also submitted for analyses. There are two types of spiked samples. The first is a field spike that is made up independently of the chemist doing the analyses. One of these trains is set up for each day of sampling. The second type of spike is the laboratory spike. These are either field spikes or samples that have additional mercury added and then analyzed. The spikes were required to be

Table 24. Reagent Blank Analysis Results

\begin{tabular}{lc}
\hline Reagent & Hg Solution, $\boldsymbol{\mu g} / \mathbf{L}$ \\
\hline $\mathrm{KCl}$ Reagent Blank & $<0.03$ \\
$\mathrm{H}_{2} \mathrm{O}_{2}$ Reagent & $<0.03$ \\
$\mathrm{KMnO}_{4}$ Reagent Blank & $<0.03$ \\
Deionized Water & $<0.03$ \\
Hydroxylamine & $<0.03$ \\
$10 \% \mathrm{HNO}_{3}$ Blank & $<0.03$ \\
$0.1 \mathrm{~N} \mathrm{HNO}_{3}$ & $<0.03$ \\
\hline
\end{tabular}


Table 25. Results of Mercury Speciation Field Blanks

\begin{tabular}{|c|c|c|c|}
\hline Day & $\begin{array}{c}\mathrm{KCl} \\
\text { Solution, } \mu \mathrm{g} / \mathrm{L} \\
\end{array}$ & $\begin{array}{c}\mathrm{H}_{2} \mathrm{O}_{2} \\
\text { Solution, } \mu \mathrm{g} / \mathrm{L} \\
\end{array}$ & $\begin{array}{c}\mathrm{KMnO}_{4} \\
\text { Solution, } \mu \mathrm{g} / \mathrm{L} \\
\end{array}$ \\
\hline 1 & $<0.03$ & $<0.03$ & $<0.03$ \\
\hline 2 & $<0.03$ & $<0.03$ & 0.08 \\
\hline 3 & 0.03 & 0.08 & 0.03 \\
\hline 4 & $<0.03$ & $<0.03$ & 0.03 \\
\hline 5 & $<0.03$ & $<0.03$ & $<0.03$ \\
\hline 6 & $<0.03$ & $<0.03$ & $<0.03$ \\
\hline 7 & $<0.03$ & $<0.03$ & 0.03 \\
\hline 8 & $<0.03$ & $<0.03$ & 0.17 \\
\hline
\end{tabular}

Table 26. Summary of Results of Mercury Speciation Spikes

\begin{tabular}{|c|c|c|c|c|c|c|c|c|c|c|c|}
\hline \multicolumn{4}{|c|}{ Field Spikes } & \multicolumn{4}{|c|}{$\begin{array}{l}\text { Laboratory Spikes on Field } \\
\text { Spikes, ppb }\end{array}$} & \multicolumn{4}{|c|}{$\begin{array}{c}\text { Laboratory Spikes on Samples, } \\
\text { ppb }\end{array}$} \\
\hline Sol. & Spike & Avg. & $\begin{array}{l}\text { Std. } \\
\text { Dev. }\end{array}$ & Sol. & Spike & Avg. & $\begin{array}{l}\text { Std. } \\
\text { Dev. }\end{array}$ & Sol. & Spike & Avg. & $\begin{array}{l}\text { Std. } \\
\text { Dev. }\end{array}$ \\
\hline $\mathrm{KCl}$ & 2 & 2.14 & 0.07 & $\mathrm{KCl}$ & 2 & 2.04 & 0.08 & $\mathrm{KCl}$ & 1 & 1.09 & 0.07 \\
\hline $\mathrm{H}_{2} \mathrm{O}_{2}$ & 1 & 0.89 & 0.23 & $\mathrm{KCl}$ & 5 & 5.38 & 0.12 & $\mathrm{KCl}$ & 2 & 2.04 & 0.09 \\
\hline \multirow[t]{4}{*}{$\mathrm{KMnO}_{4}$} & 2 & 2.07 & 0.10 & $\mathrm{H}_{2} \mathrm{O}_{2}$ & 1 & 0.91 & 0.28 & $\mathrm{H}_{2} \mathrm{O}_{2}$ & 1 & 0.97 & 0.11 \\
\hline & & & & $\mathrm{H}_{2} \mathrm{O}_{2}$ & 2 & 2.06 & 0.34 & $\mathrm{H}_{2} \mathrm{O}_{2}$ & 2 & 2.02 & 0.18 \\
\hline & & & & $\mathrm{KMnO}_{4}$ & 1 & 1.06 & 0.07 & $\mathrm{KMnO}_{4}$ & 1 & 1.01 & 0.01 \\
\hline & & & & $\mathrm{KMnO}_{4}$ & 2 & 2.03 & 0.07 & $\mathrm{KMnO}_{4}$ & 2 & 2.01 & 0.03 \\
\hline
\end{tabular}

within $10 \%$ of the true value. The solution used for spiking was from a separate stock as the calibration standards. A summary of the analytical results for the spiked samples is shown in Table 26. As can be seen, the analysis of these spikes is within the tolerance specified. The actual data sheets are available in the Appendices.

\subsection{CONCLUSIONS}

On the basis of the results from the sampling program at the Blount Station, the following conclusions can be made:

- Regardless of fuel, about $40 \%$ of the mercury generated at the Blount Station is in the form of particulate-bound mercury and is removed by the ESP. 
- For all fuel conditions, there was an increase in measured vapor-phase mercury across the ESP. Most likely, this was due to additional mercury capture by the fly ash collected on the $\mathrm{OH}$ method filter.

- Good mass balances were obtained for each test condition.

- Adding PDF to the coal resulted in decreased mercury emissions at the stack.

- The addition of paper to the fuel mix resulted in greater mercury reduction than plastic.

- As would be expected, the addition of a high-chloride plastic to the fuel mix increased the level of chloride in the flue gas. But this increase did not appear to affect mercury speciation.

- The Semtech Hg 2010 and the Tekran CEMs both gave good total mercury results when compared to the $\mathrm{OH}$ method. Although limited data were obtained, both CEMs gave good speciation results.

\subsection{REFERENCES}

1. U.S. Environmental Protection Agency. Airlink Web Site at: http://www.epa.gov/airlinks (accessed Aug 11, 2000).

2. Lindqvist, O.; Rodhe, H. Atmospheric Mercury - A Review. Tellus 1985, 387B, 136-159.

3. Laudal, D.L.; Galbreath, K.C.; Heidt M.K. A State-of-the-Art Review of Flue Gas Mercury Speciation Methods; EPRI Report No. TR-107080 3471; Nov 1996.

4. Laudal, D.L.; Heidt, M.K. Evaluation of Flue Gas Mercury Speciation Methods; EPRI Report No. TR-108988; Dec 1997.

5. Carey, T.R.; Hargrove, O.W., Jr.; Richardson, C.F.; Chang, R.; Messerole, F.B. Factors Affecting Mercury Control in Utility Flue Gas Using Sorbent Injection. Presented at the Air \& Waste Management Association 90th Annual Meeting \& Exhibition, Toronto, ON, Canada; June 1997; Paper No. 97-WA72A.05.

6. Miller, S.J.; Dunham, G.E.; Olson, E.S.; Brown, T.D. Controlling Mechanisms That Determine Mercury Sorbent Effectiveness. Presented at the Air \& Waste Management Association 92nd Annual Meeting \& Exhibition, St. Louis, MO, June 1999; Paper No. 99-898.

7. Miller, S.J.; Ness, S.R.; Weber, G.F.; Erickson, T.A.; Hassett, D.J.; Hawthorne, S.B.; Katrinak, K.A.; Louie, P.K. A Comprehensive Assessment of Toxic Emissions from Coal-Fired Power Plants: Phase I Results from the U.S. Department of Energy Study; Report for U.S. Department of Energy Contract No. DE-FC21-93MC30097; Energy \& Environmental Research Center: Grand Forks, ND, Oct 1996. 